\title{
El No Lugar de la militancia femenina en el Movimiento de Izquierda Revolucionaria, MIR
}

The non-place of the female membership within the Revolutionary Left Movement, MIR

Tamara Vidaurrázaga Aránguiz*

Resumen: En este artículo utilizaremos la teoría feminista y de género respecto de la división de las esferas público-privada y los cautiverios femeninos, para reflexionar respecto de las dificultades de la militancia femenina y la posibilidad de lograr un lugar en una organización político militar como el Movimiento de Izquierda Revolucionaria MIR en Chile, a partir del análisis de testimonios de las propias militantes de esta orgánica, así como documentos partidarios. Proponemos que en el tránsito desde el rol de la madresposa mandatado por la feminidad hegemónica, hacia el guerrillero -históricamente masculino y masculinizante- estas militantes pasan por un espejismo de igualdad como resultado de un esfuerzo por mostrar que tienen lo suficiente, acabando en un No Lugar, en tanto el final del trayecto les está negado sexo-genéricamente, y a pesar de lo que incurren en transgresiones inusitadas para esta generación.

Palabras clave: Militancia femenina, dicotomía público-privado, No lugar, MIR Chile, madresposa.

\begin{abstract}
In this article, we reflect from a feminist perspective on the division of the private and public spheres and the female captivities to analyze the difficulties of female political membership and the posibilities of being part of an armed political organization like the Revolutionary Left Movement (MIR) in Chile, based on the testimony of women of this organization and on their official party documentation. We propose that in the transition from the role of 'madresposa' (mother and wife) mandated by hegemonic femininity, to the guerrilla -historically male and masculinizing- these militants go through an illusion of equality as a result of an effort to show that they have enough, ending in a non-place, as the end of the journey is denied sex-generically, despite that they incur in transgressions unusual for this generation.
\end{abstract}

Keywords: Female militancy, public-private dichotomy, Non-place, MIR Chile, madresposa.

Recibido: 12 marzo 2019 Aceptado: 27 mayo

\footnotetext{
* Chilena, Doctora en Estudios Latinoamericanos, Universidad Academia de Humanismo Cristiano. Este artículo es un producto de la investigación del Proyecto CONICYT-Fondecyt de Iniciación No 11170200 "Voces intergeneracionales: madres e hijos en el contexto de la militancia de la Nueva Izquierda Revolucionaria del Cono Sur en la historia reciente (Argentina, Chile y Uruguay)". tamaravidaurrazaga@yahoo.es
} 
En el presente artículo utilizamos la teoría de género y feminista para preguntarnos acerca de las dificultades que vivieron las militantes del Movimiento de Izquierda Revolucionaria MIR en Chile, al integrar una orgánica que -a pesar de auto definirse como revolucionaria- reprodujo la jerarquía y dicotomización devenida del liberalismo de las esferas público y privada, así como sus asignaciones a la masculinidad y feminidad mandatadas.

En esta lógica binaria y excluyente propia del patriarcado, la participación de mujeres en espacios de política formal ha sido históricamente una transgresión al sistema sexo género hegemónico, subversión que se agudiza en el caso de aquellas que integraron orgánicas que propugnaron la lucha político-armada, lugar dirigido y habitado mayoritariamente por varones, y que ha funcionado con los códigos de la masculinidad dominante.

El llamado del MIR hacia las mujeres fue a sumarse al proyecto revolucionario en pie de igualdad respecto de los varones militantes, y ellas mismas señalan en sus testimonios que vivieron aquello que llamamos "espejismo de igualdad", o sea la ilusión momentánea de sentirse iguales a sus compañeros ${ }^{1}$. Sin embargo, el paso del tiempo y las condiciones devenidas de ser mujeres en espacios histórica y simbólicamente ajenos, les fue evidenciando que no era lo mismo ser mujer u hombre dentro de la organización.

Para comprender la magnitud de la transgresión en que incurrieron estas mujeres al militar, utilizaremos la noción de "cautiverios femeninos" de la antropóloga mexicana Marcela Lagarde, y especialmente el concepto de "madresposa"2. Con ello nos referimos al principal mandato asignado a la feminidad en un sistema de género patriarcal, claustro que concentra a las mujeres en el espacio del adentro y el bienestar concreto de los suyos.

Esta subversión es patente en militancias como las que analizamos, en las que el mandato fue poner los esfuerzos en lo público y colectivo, donde sucedería la transformación radical y anhelada, dejando en un lugar secundario aquello que el crítico argentino Nicolás Casullo señala irónicamente como aquellas "cuestiones sin importancia" 3 .

Así, lo referido a la esfera de lo privado no estuvo en cuestión, asumiendo que en ese espacio no existían relaciones de poder necesarias de cuestionar y transformar. Solo cuando las demandas de este espacio fueron relevantes para la consecución del proyecto revolucionario la orgánica se vio presionada a solucionar colectivamente temas de la vida cotidiana.

Ello se evidencia -en el caso del MIR- cuando las mujeres quisieron unirse al llamado de la dirección partidaria que a fines de los setenta convocó a la Operación Retorno. Esta política implicó que la militancia exiliada retornara clandestinamente a Chile luego de instruirse política y militarmente con el fin de serla vanguardia que lograra derrocar a la dictadura cívico militar de Pinochet (1973-1990).

En este contexto, y cómo veremos más adelante, las mujeres que quisieron unirse a esta política, demandaron una solución partidaria para el cuidado de infantes, erigiéndose el "Proyecto Hogares" en el que se cuidó a los hijos e hijas de la militancia retornada.

Es en este marco, que nos preguntamos acerca de la posibilidad que tuvieron las miristas de encontrar un lugar sexo genérico en este tránsito subversivo entre la madresposa -del adentro- y el guerrillero -completamente entregado hacia el afuera y dicho a propósito en masculino-. Reflexionamos también respecto de las contradicciones que tuvo esta trayectoria, asi como sobre las posibilidades que emergieron para ellas y la orgánica que integraron.

Este trabajo es resultado de dos investigaciones de postgrado ${ }^{4}$, en las que se analizaron documentos partidarios y testimonios de mujeres militantes del MIR, quienes cumplieron labores

\footnotetext{
${ }^{1}$ Gaviola, Edda, Largo, Eliana y Palestro, Sandra, Una historia necesaria: mijeres en1973-1990, LOM, 2007.

2 Lagarde, Marcela, Los cautiverios de las mujeres: madresposas, monjas, putas, presas y locas, Madrid, HORAS y horas, 2011.

${ }^{3}$ Casullo, Nicolás, Las Cuestiones, Buenos Aires, Fondo de Cultura Económica, 2007.

4 Vidaurrázaga, Tamara, Mujeres en Rojo y Negro. Reconstrucción de memoria de tres mujeres miristas, Santiago, Escaparate, 2006; Tesis

Las combatientes. Militancias Femeninas en la Nueva Izquierda Revolucionaria Latinoamericana: Miristas Chilenas y Tupamaras Uruguayas
} 
profesionales al interior de la organización, entendiendo por ello una dedicación exclusiva y/o prioritaria al proyecto político. Las entrevistas fueron realizadas personalmente en torno a periodos de sus militancias que oscilan entre los años de la Unidad Popular previos al Golpe de Estado, hasta la división definitiva del MIR (1970-1987).

Al ser testimonios recogidos posteriormente al $2000^{5}$, es importante comprender que la mirada respecto de ese pasado militante reciente esta mediada por el paso del tiempo, y por tanto permite críticas y reflexiones que antes no siempre fueron posibles. Asimismo, que los testimonios no son necesariamente un espejo de lo sucedido, sino, resultado de cómo ese pasado se reelabora buscando ser coherente con quién se es en este presente, y con las herramientas adquiridas posteriormente a los hechos.

A este corpus de análisis también agregamos testimonios de miristas ya publicados en biografías, memorias o investigaciones, así como documentos partidarios de la época referidos a los comportamientos esperables por parte de la militancia, lo que nos ayuda a ampliar la gama de perspectivas y también a conocer lo que la organización mandató y esperaba de quienes la integraban.

El MIR chileno (1965-1987) se declaró marxista-leninista, siguió las políticas acordadas en OLAS (Organización Latinoamericana de la Solidaridad) en Cuba y fue parte de la Nueva Izquierda Revolucionaria latinoamericana ${ }^{6}$. Este sector político propugnó la lucha armada y sin alianzas con la burguesía, y se caracterizó por una moral militante revolucionaria coherente con el guevarismo y el ideal del Hombre $\mathrm{Nuevo}^{7}$, caracterizada por desatender lo personal e individual en pos de fortalecer la lucha por el proyecto revolucionario, siempre entendido como algo sucedido en la público y colectivo ${ }^{8}$.

Así, hubo escaso cuestionamiento a otros tipos de desigualdades y discriminaciones que entonces se asumieron como contradicciones secundarias que se resolverían en un futuro, como la razaetnia o el sexo-género, asumiendo que el combatiente era un ser neutro.

En el amplio periodo estudiado hubo momentos diversos ${ }^{9}$, con niveles de exigencia distintos para sus militancias según el nivel de peligro al que se enfrentaban, sin embargo se mantuvo transversalmente esta moral militante revolucionaria compartida por la Nueva Izquierda, que fue anhelo y elección de quienes integraron esta orgánica, pero también mandato para poder mantenerse en ella ${ }^{10}$.

\section{Acerca de la dicotomización de las esferas pública y privada}

Unas de las características del patriarcado como sistema sexo género hegemónico, es la configuración de la cultura y la sociedad basándose en una estructura rígida y binaria que dicotomiza los

(1965-1987) (2015). Doctorado de Estudios Latinoamericanos, Centro de Estudios Latinoamericanos, Facultad de Filosofía y Humanidades, Universidad de Chile.

5 Las entrevistas fueron realizadas entre los años 2002 y 2014.

${ }^{6}$ Goicovic, Igor, Movimiento de Irquierda Revolucionaria, Santiago, Escaparate, 2012; Pinto, Julio y Leiva, Sebastián, "Punto de quiebre. El MIR en los ochenta”, Verónica Valdivia, Rolando Álvarez, Julio Pinto, Karen Donoso, Sebastián Leiva (eds.), Su revolución contra nuestra revolución, Volumen II, La pugna marxista-gremialista en los ochenta, Santiago, LOM, 2008; Sandoval, Carlos, de Izquierda Revolucionaria 1965-1970. Coyunturas, documentos y vivencias, Tomo I, Santiago, Quimantú, 2014, Löwy, Michael, El Pensamiento Del Che Guevara, Buenos Aires, Siglo XXI, 1985.

7 Vidaurrázaga, "El pecado pequeño burgués en las organizaciones de la nueva izquierda revolucionaria latinoamericana. MIR chileno y MLN-T uruguayo", Estudios, 34, Julio-Diciembre, 2015b.; Longoni, Ana, "El mandato sacrificial", Revista Ciencias Sociales, 67, julio, 2007.

8 Vidaurrázaga, Tamara, "La escisión entre lo individual y lo colectivo en la moral revolucionaria militante de la Nueva Izquierda”, Sujeto, Subjetividad y Cultura, 4, Escuela de Psicología, Universidad Arcis, 2012.

${ }_{9}$ El historiador chileno Igor Goicovic (op. cit.) señala los siguientes periodos para la historia de esta organización: Fundación (1965-1967); Reorganización (1967-1970); Unidad Popular (1970-1973); Golpe, Aniquilamiento y reorganización de la resistencia (1973-1978); Operación Retorno y ofensiva (1978-1982); y Reanimación de los movimientos populares (1982-1987), agregando la etapa de la división.

10 Vidaurrázaga, 2015, op. cit, Ruíz, María Olga "Mandatos militantes, vida cotidiana y subjetividad revolucionaria en el Movimiento de Izquierda Revolucionaria de Chile (1965-1975)”, Revista Austral de Ciencias Sociales, 28, pp. 163-182, 2015. 
sexos-géneros asumiendo que solo existen dos posibilidades (macho-masculino/hembra-femenina), y que estas son excluyentes, organizando así las esferas sociales, los roles y los mandatos.

En este binarismo dicotómico, el mundo también ha sido comprendido como si estuviera dividido en dos: aquello que sucede en lo público y del afuera -hábitats de la masculinidad y los hombres- y aquello sucedido en lo privado y el adentro -lugar apropiado para la feminidad y las mujeres-.

Esta división además de arbitraria ha sido jerarquizada, como plantea la filósofa española Celia Amorós, señalando que la esfera pública es más valorada por ser lugar del reconocimiento de lo visible y encontrarse expuesto a la mirada pública, y el espacio en que habría competencia entre seres individuales y diferenciados.

La esfera de lo privado -en cambio- sería el de las idénticas, lugar donde la historia no pasa, vinculándose históricamente con lo sacro. Ahí habitaría aquello que se sustrae a la mirada, porque es un espacio donde no hay poder a repartir dado que son las mujeres las repartidas, por tanto, no "hay razón para marcar el ubi-diferencial: éste ya está marcado por la privacidad de los espacios a que la mujer está adjudicada de una u otra forma, mientras que en el espacio público uno se ha de sellar respecto al otro, y al tercero, que no es yo porque es otro, pero es otro que es como yo"11.

Para la teoría feminista, la diferencia de valoración entre una y otra esfera se originan con el liberalismo ilustrado, cuando el suizo Jean Jacques Rosseau definió el contrato social como un espacio de libertad y democracia que sucede en lo público, mientras lo privado fue comprendido como parte de la naturaleza y un lugar en el que por tanto resulta innecesario intervenir contractualmente ${ }^{12}$.

Así, la esfera privada no se consideró políticamente, y el contrato del matrimonio -y el patriarcado evidenciados en el espacio de la familia- resultaron irrelevantes públicamente ${ }^{13}$. Ello, porque las relaciones de poder que tensan el espacio del adentro fueron invisibilidades, negándose como construcciones socio-culturales que por tanto pueden cuestionarse y transformarse en búsqueda de la prometida igualdad liberal.

El pensamiento político ilustrado justificará la existencia de un Estado o cuerpo político que puede obligar al hombre libre, sin embargo "este convenio se contrata exclusivamente en el dominio de los asuntos públicos, que se supone son los que tienen trascendencia política. La esfera de lo privadofamiliar, y la mujer que por ella se define, permanece regida por una suerte de ley divina o natural y atada al antiguo derecho sacro" 14 .

La esfera privada, que es íntima, lugar del hogar y lo familiar, es un espacio donde el patriarca sigue ejerciendo un poder no consensuado, un lugar donde no existe la igualdad, esfera en la cual carecen de relevancia las cuestiones de la justicia ${ }^{15}$. La búsqueda de libertad y democracia del liberalismo entonces, sería solo en el espacio político de lo público, mientras que en el espacio íntimo de lo privado se permitiría toda clase de abusos de poder, sin más regulación que la libertad total del patriarca, justificada por la naturaleza de las relaciones hombre-mujer al interior de las familias.

La feminista británica Carole Pateman, llama a ese supuesto libre albedrío de lo íntimo -en contraposición al contrato social de lo público- el "contrato sexual", señalando categóricamente que el "contrato social es una historia de libertad, el contrato sexual es una historia de sujeción" 16 . Con ello indica que en lo privado también existiría un contrato, pero del que no se habla, quedando en el olvido,

11 Amorós, Celia, “Espacio público, espacio privado y definiciones ideológicas de 'lo masculino' y 'lo femenino'”, Feminismo, igualdad y diferencia, México, UNAM, 1994, p. 3.

12 Fraisse, Geneviève, Los dos gobiernos: la familia y la ciudad, Madrid, Cátedra, 2003.

13 Beltrán, Elena, "Público y privado (Sobre feministas y liberales: argumentos en un debate acerca de los límites de lo político)", Debate Feminista, año 9, volumen XVIII, México, 1998, p. 21.

14 Molina, Cristina, "Dialéctica feminista de la Ilustración", Barcelona, Antrophos, Madrid, Comunidad de la mujer, 1994, p. 36-37.

15 Beltrán, op cit., p. 8.

16 Pateman, Carole, El contrato sexual, Barcelona, Anthmpos, México, Universidad Autónoma Metropolitana - Iztapalapa, 1995, p. 10. 
como moneda de cambio para la instauración del contrato social. Así, contrato social y patriarcado serían cómplices de este olvido intencional.

El contrato sexual sería, entonces, el medio a través del cual el patriarcado moderno se constituye, pacto originario que sería "tanto un pacto sexual como un contrato social, es sexual en el sentido de que es patriarcal -es decir, el contrato establece el derecho político de los varones sobre las mujeres- y también es social en el sentido de que establece un orden de acceso de los varones al cuerpo de las mujeres" 17 .

Este orden de acceso de los varones al cuerpo de las mujeres, implica que en efecto hay jerarquías entre los propios varones, etarias, pero también de clase, sin embargo, supone un pacto colectivo donde todos son depositarios de un poder por sobre ellas. Por esto, la marxista Heidi Hartmann señala que el salario familiar es un pacto patriarcal interclasista entre varones de clases sociales en pugna, con el objetivo de controlar socialmente a las mujeres. Los varones patrones pactarían entonces con otros varones proletarios, y estos últimos optarían por el pacto con el patrón antes que por la complicidad con sus compañeras de clase ${ }^{18}$.

Lo público y lo privado, se vinculan con otros binarismo, de los cuales nos interesa resaltar uno que también resultó escindido dicotómicamente en organizaciones de la Nueva Izquierda revolucionaria como el MIR: Lo colectivo y lo individual ${ }^{19}$. Hacemos la vinculación entre estos dos pares de espacios sociales, puesto que, como señala la filósofa mexicana Nora Rabotnikof:

\begin{abstract}
el criterio para el trazado de la distinción es la referencia al colectivo o a la dimensión individual. Así, público alude a lo que es de interés o utilidad común a todos, lo que atañe al colectivo, lo que concierne a la comunidad, en oposición a lo privado, entendido como aquello que refiere a la utilidad e interés individuales (...) En oposición, en esta primera acepción, lo privado designa lo que es singular y particular que, en su origen, pretende sustraerse a ese poder público (entendido como poder del colectivo $)^{20}$
\end{abstract}

En la misma línea, Pateman señala como parejas antagónicas y que se desprenden de lo público y privado, los conceptos de personal y político, amor y justicia, individualidad y comunalidad; cuestiones que dejan de un lado las nociones de lo público-político-justicia-comunalidad o colectividad como cuestiones ligadas a los hombres y la masculinidad, y que tendrían un mayor valor en relación a aquellas ligadas a las mujeres y la feminidad, o sea, lo privado-personal-amor-individualidad. Estas dicotomías no desaparecieron, sino que se acentuaron con el liberalismo patriarcal21.

\title{
El cautiverio de la madresposa y la noción del No Lugar
}

En una sociedad patriarcal, las mujeres se supeditan a los mandatos de la feminidad hegemónica, que las ubica en lo que la feminista mexicana Marcela Lagarde 22 llama los cautiverios. Con ello refiere a la expresión político-cultural de la condición de las mujeres, señalando que todas están cautivas de su condición genérica solo por el hecho de serlo y vivir en el patriarcado. Los cautiverios femeninos serían entonces esos lugares -cerrados y rígidos- en los cuales las sociedades encierran a las mujeres, y en los que existen reglas que cumplir.

${ }^{17}$ Idem.

18 Hartmann, Heidi, "Un matrimonio mal avenido: hacia una unión más progresiva entre marxismo y feminismo", Zona Abierta, $\mathrm{n}^{\circ} 24,1980$.

19 Vidaurrázaga, Tamara, op. cit. 2012.

20 Rabotnikof, Nora, "Privado-público", Debate Feminista, año 9, volumen XVIII, México, 1998, p. 4.

21 Pateman, op. cit., p. 22.

22 Lagarde, op. cit. 
Estos enclaustramientos restringen las libertades de las mujeres, significando conflictos y sufrimientos para ellas, y al unísono deseos por cumplir con esos mandatos, existiendo lo que la antropóloga llama "felices cautivas", ya que “(...) la felicidad femenina se construye sobre la base de la realización personal del cautiverio que, como expresión de feminidad, se asigna a cada mujer" 23. Así, ellas viven tensionadas entre el malestar de la imposición y el deseo de cumplir con ella, con el fin de ser reconocidas socialmente como "buenas mujeres".

Lagarde analiza estos cautiverios, en los que la sexualidad femenina es central, ya sea como sexualidad reproductora o erótica, y pudiendo ser vivida o reprimida, pero siempre escindida. Estos enclaustramientos mandatan cómo se debe vivir o renunciar a estas dos formas de sexualidad femenina, imposibilitando la libertad de elección, aquello que De Beauvoir -desde el existencialismo- denominó el proyecto elegido en libertad, cuestión que para la francesa posibilitaría la trascendencia, históricamente restringida a la masculinidad.

De los cautiverios, nos interesa particularmente el de la "madresposa", aquel en que ellas permanecen "cautivas de y en la maternidad y la conyugalidad, con su entrega a cambio de un erotismo subsumido, negado, la filiación, la familia y la casa"24.

Al igual que la Virgen María, la madresposa está enclaustrada en una sola posibilidad: la renuncia a su sexualidad erótica en función de su sexualidad reproductora, implicando entregarse por completo y vivir en función de otros. Cautiverio donde lo conyugal y la maternidad son primordiales, y que sería la realización en plenitud de una mujer en un sistema patriarcal, puesto que el "primer parto es el ritual simbólico del nacimiento de la verdadera mujer: la madre"25.

Así, todas las mujeres son madresposas, aunque no tengan hijos ni esposo, solo por nacer hembras, puesto que éste es el rol que se espera todas cumplan a cabalidad, en detrimento incluso de sí mismas y sus propios yo deseantes.

Estas militantes transitan por más de un cautiverio, sin embargo, el claustro de la madresposa es el que se esperaba en general por parte de ellas antes de salir de sus hogares de crianza, ya fuera por parte de las familias, ya fuera por la sociedad. Los testimonios dan cuenta de mujeres preparadas familiar, social y culturalmente para convertirse en madresposas, por supuesto con diferencias entre sí y con la posibilidad -dada la época- de acceder a estudios superiores o al trabajo remunerado, cuestión que se repite como una constante en los testimonios analizados. Así, se aceptaba que las labores de madresposa se pospusieran temporalmente por los estudios, el trabajo o el desarrollo personal, siempre y cuando finalmente se desarrollara y fuera prioridad en la vida de las mujeres de esta generación.

Respecto de la noción del No Lugar, la utilizamos desde una perspectiva de género, entendiendo que hay un sitio acotado para la feminidad mandatada: el de lo privado y el mundo del adentro. $\mathrm{Y}$ que a partir de esa norma sexo-genérica, y también en términos históricos, existen espacios que han sido habitados mayormente por varones, y construidos desde y para la masculinidad dominante, en los que las mujeres han sido escasas, ocasionales y sistemáticamente extranjeras. Ello se hace evidente en el mundo de la política formal y se agudiza en el caso de organizaciones políticoarmada.

Este concepto proviene originalmente de la arquitectura, cuando Robert Smithson refiere los Non-sites, denominando así un sitio representado que -en su representación- no se parece en nada al real, e incluso señalando que pueden haber "itinerarios ficticios" cuando se realiza un No-viaje desde un sitio a un no-sitio ${ }^{26}$.

Desde la geografía, un lugar es precisamente lo contrario a lo planteado por Smithson: un conjunto de coordinadas situadas en un mapa que fijan un territorio bien definido y delimitado. Pero esta disciplina también señala que el espacio es conflictivo, fluido e inseguro, puesto que lo que define

\footnotetext{
23 Ibid., p. 66.

24 Ibid., p. 197.

25 Ibid., p. 393.

${ }^{26}$ Smithson, Robert, A provisional theory of Non-sites, 1968.
} 
el lugar son prácticas socio-espaciales en las que existen relaciones sociales de poder y de exclusión; por lo que los espacios se superponen y entrecruzan y sus límites son variados y móviles ${ }^{27}$.

Tal como señala la geógrafa feminista Linda McDowell28, los espacios surgen de las relaciones de poder y se vinculan con estas, estableciendo normas que a su vez definen límites sociales y espaciales al determinar quién pertenece a un lugar y quien queda excluido del mismo.

Así, las distancias sociales no siempre requieren lejanías geográficas, y los ocupantes del mismo espacio cartesiano pueden vivir en lugares distintos, existiendo lo que ella llama una geografía de las relaciones de género. Ello resulta evidente, por ejemplo, al interior de una familia, donde el padre y la madre -aun habitando el mismo espacio en términos del plano- ocupan lugares diferentes devenidos de los mandatos de género y lo que estos permiten o no en relación a los cuerpos con los que vinieron al mundo. Estas fronteras, aun no visiblemente marcadas dentro del hogar, son evidentes y se reproducen por los otros miembros de las familias como la más clara de las fronteras geográficas. Por ello McDowell señala que:

las relaciones de género interesan también a las geógrafas porque las divisiones espaciales -público y privado; dentro y fuera- tienen una importancia fundamental para la construcción social de las divisiones de género. La asignación a la mujer de un lugar concreto no es sólo la base de un amplio abanico de instituciones que van de la familia al puesto de trabajo, o del centro comercial a las instituciones políticas, sino también un aspecto esencial del pensamiento ilustrado occidental, de la estructura y división del conocimiento y de los temas que deben estudiarse dentro de tales divisiones ${ }^{29}$.

Así, el cuerpo de las mujeres sería el lugar donde reside la opresión de un sistema que las remite a los espacios de lo privado, del adentro, de lo personal, de la naturaleza; asumiendo que el cuerpo de los varones sería entonces el adecuado para habitar los espacios públicos, del afuera, donde lo colectivo se debate, y de la cultura. Ello porque -tal como indica McDowell- "el espacio y el lugar son sexuados y tienen un carácter de género, y las relaciones de género y la sexualidad están 'espacializadas"”30.

Por supuesto, tener un lugar asignado en el mundo implica siempre la posibilidad de moverse en las fronteras de este o incluso la posibilidad de intentar abandonarlo, cuestión que es más evidente cuando nos referimos a espacios mandatados arbitrariamente por la cultura a partir de cuerpos sexuados. Por ello existiría lo que McDowell llama "cuerpos fuera de lugar" 31 , señalando así la ocupación de un espacio que debiera estar negado y sin embargo se habita.

En el caso de estas militantes, sus participaciones en espacios político-militares transgreden la división sexual de las esferas público-privada, y además la vinculación simbólica mujer-madre-dadora de vida, hombre-guerrero-capaz de quitar la vida. Díada que -para De Beauvoir- relega a las mujeres a la inmanencia repetitiva de la procreación y el cuidado de otros, reservando para los varones la posibilidad de quitar o entregar la vida por el prestigio de la horda, lo que en términos sociales y culturales sería más valorado y le restaría valor a la procreación en tanto releva la posibilidad de elegir un proyecto para sí, y por tanto trascender ${ }^{32}$.

\footnotetext{
27 Smiti, I, N. (1993), "Homeless/global: scaling places”, en J. Bird, B. Curtis, T. Putnam, G Robertson y L. Tickner (eds.), Mapping the Futures: Local Cultures, Global Change, Londres, Routledge, 1993; Massey, D y Jess, P, (1995) (eds.), A Place in the World? Places, Culture and Globalisation, Oxford, Oxford University Press, 1995. Referenciados en McDowell, Linda, Género, identidad y lugar: un estudio de las geografías feministas, Madrid, Cátedra, 2000.

${ }_{28}$ McDowell, op. cit.

${ }^{29}$ Ibid., p. 27.

30 Ibid., p. 101.

31 Ibid., p. 91.

32 De Beauvoir, Simone, El segundo sexo, México, Debolsillo, 2013.
} 
Esta transgresión es precisamente la que provoca que las militantes fueran estereotipadas y temidas, en tanto -aun teniendo la posibilidad, mandato e incluso deseo de procrear-, decidieron salir del espacio del adentro, lo privado e individual, para comprometerse con un proyecto que implicaba la posibilidad de matar o morir, y significándoles habitar un lugar ajeno, tanto en términos históricos como simbólicos.

Para el francés Michel De Certau ${ }^{33}$, andar -refiriéndose al vagabundeo en la ciudad- es no tener un lugar, en tanto implica un proceso indefinido de "estar ausente y en algo propio", buscando nolugares o lugares soñados en esta caminata. Así, al perder el sitio propio, su colocación en el orden del mundo, el individuo nacería como sujeto, abriéndose a un "No Lugar" identitario que solo tiene incertezas.

Este tránsito entre el lugar conocido y mandatado y el lugar anhelado de la incertidumbre, diferenció a estas militantes de sus congéneres, implicando la militancia una huida radical desde el cautiverio de la madresposa, como lugar definido, y un viaje hacia el sitio deseado del guerrillero, al que no existe certeza de llegar, en tanto no les corresponde habitarlo.

Primero, porque tener un proyecto político prioritario era señal de un proyecto para sí y por tanto trascendente; segundo, porque las ubicó en un espacio histórica y culturalmente vinculado con la masculinidad hegemónica, como es el mundo público y colectivo de la política y de las armas; tercero, porque el proyecto elegido fue opuesto a las labores de la madresposa, teniendo como foco de atención la humanidad en abstracto antes que un círculo familiar restringido y concreto,

Las militancias político-militares subvirtieron, así, uno de los mandatos fundamentales de la feminidad hegemónica: entrega y dedicación exclusiva y excluyente hacia otros concretos, puesto que, por "(...) el amor las mujeres disponen sus vidas para los otros. El amor de las mujeres es otorgado en exclusiva a los miembros del grupo doméstico, si este se reduce, se reducen las posibilidades amorosas de las mujeres. La mujer no es solo monógama, sino monoamorosa y debe ser monomadre" 34 , señala Lagarde. Para las militantes de estas orgánicas se ampliaron las nociones de familia al partido, y los objetos amorosos se trasladaron desde las personas cercanas -los hijos propios y la familia- a seres genéricos que motivaron la entrega total al proyecto abstracto, público y colectivo de la revolución -todos los niños del mundo, toda la gente pobre-.

Para los historiadores chilenos Julio Pinto y Gabriel Salazar ${ }^{35}$, este rasgo fue compartido por toda la "generación rebelde del 68", caracterizándose por romper con la familia y priorizar por el partido, relegando también la profesión, diversión, pareja, y apariencia a un plano secundario u olvidado. Así, la colectividad pasó a un nivel superior en el que la individualidad debía diluirse hasta desaparecer. Los otros, el pueblo, las masas oprimidas eran más relevantes que la vida propia, de lo contrario se daban muestra de egoísmo que remitía a un pecado pequeño burgués que el militante mirista debía haber extirpado ${ }^{36}$. Esto resultó en posponerse a sí mismos, pero también en ubicar en un lugar secundario los cariños cercanos, personales y concretos, como la familia. Ello, que ha sido parte de la historia de la masculinidad y algo esperable para varones que priorizaran por un proyecto trascendente y abstracto, fue una subversión radical en el caso de mujeres socializadas para la feminidad y el mundo concreto del adentro.

\section{Liberarse para ser un soldado más}

En los setenta una miliciana mirista señaló a la publicación El Rebelde, órgano oficial del MIR, que "los hombres y las mujeres debemos pelear juntos, aunque nosotras tengamos también que lavar, planchar o

\footnotetext{
33 Certeau, Michel, La invención de lo cotidiano, México, D.F, Universidad Iberoamericana, A.C., 1996.

34 Lagarde, op. cit., p. 184.

35 Salazar, Gabriel y Pinto, Julio, (Con la colaboración de Muñoz, V. y Toro, M. S.),. Historia contemporanea de chile. Tomo V. Niñezy juventud, Santiago, LOM, 2002.

36 Vidaurrázaga, 2015b, op. cit.
} 
cuidar a los hijos" ${ }^{37}$. En otro texto de este mismo periódico titulado La liberación de la mujer, se dan luces respecto del papel de esta en la lucha revolucionaria, señalando que la "mujer campesina, la mujer obrera, la mujer pobladora, explotada y humillada por esta sociedad desigual e injusta contra la cual luchamos, ha empezado a movilizarse. Es allí donde la mujer juega su papel como combatiente de la revolución. Porque ellas también tienen su lugar en la lucha revolucionaria" 38 . A lo que se añade que el objetivo es "hacer de cada mujer trabajadora un soldado más en la lucha por la conquista del poder" 39.

En estas sentencias, es evidente cuál es el rol que la orgánica esperaba de las mujeres en la lucha por el socialismo: asumir su "verdadero papel", que no solo sería de madre sino también de compañera, realizando las labores del hogar y de crianza, además de luchar junto a los varones.

La lucha socialista, entonces, debía ser compartida, no así las labores de cuidado, obviándose que -para que ellas tuvieran condiciones para incorporarse en la lucha social- se requerían compañeros que a su vez se responsabilizaran de lo doméstico tanto como ellas. Así, el combate por la revolución se realizaría a costa de los tiempos, contradicciones y culpas de ellas mismas, sumándoles nuevas tareas, a las ya mandatadas social y culturalmente.

La frase que señala la importancia de hacer "un soldado más" de cada mujer, evidencia que la incorporación a la lucha revolucionaria era bajo una impronta masculina y a un territorio ajeno que, por tanto, no les pertenecía, siendo ellas convocadas a transformarse en "soldados", masculino que confirma lo ajeno de la tarea.

Las diferencias de condiciones y mandatos entre ellas y sus compañeros eran obviadas: la lucha de clases era primordial, y en esta lucha había patrones y proletarios, debiendo ellas sumarse a uno u otro bando, homogeneizándose la diversidad existente bajo la noción de proletariado. Esto se reafirma, al indicar que ellas debían unirse a la militancia “(...) para participar activamente en las luchas obreras, que no se pueden dividir por sexo, ya que el explotador no hace distinciones" 40.

Mujeres y hombres, jóvenes y adultos, indígenas y mestizos, homosexuales y lesbianas, eran subsumidos bajo el paraguas del proletariado obrero, invisibilizándose las desigualdades y discriminaciones de las que son objetos al mismo tiempo que las de clase.

En los discursos del máximo líder mirista, Miguel Enríquez, es notoria la referencia reiterada al concepto de "virilidad" asociado a la organización y su actuar, cuando -ya militando en la Vanguardia Revolucionaria Marxista-, señaló un mes antes del Congreso de Unidad Revolucionaria que daría nacimiento al MIR, "que esta IZQUIERDA REVOLUCIONARIA defienda un criterio democrático amplio, como condición orgánica para una profunda y viril vida ideológica, política y actuante del Partido Revolucionario" ${ }^{41}$.

Esta idea de virilidad es repetida por Enríquez en un discurso dado en el Congreso que dio paso a la organización, señalando que se requiere una "audaz política revolucionaria capaz de oponer a esta cínica violencia imperialista una viril y altiva respuesta de las masas armadas" 42 , y nuevamente años después, en una entrevista a Punto Final, cuando denunciaba que "cuando los estudiantes marchan por las calles, son violentamente agredidos por Carabineros, agresión a la que virilmente responden" 43 . En estos textos la palabra virilidad es utilizada como sinónimo de valentía, determinación, asociada de esta manera a la masculinidad, como una característica natural que era deseable, entonces, para la organización y su militancia.

\footnotetext{
${ }^{37}$ El Rebelde, “Liberación de la mujer”, N² 28, mayo, 1972. El destacado es nuestro.

${ }^{38}$ El Rebelde, $N^{\circ} 18$, febrero, 1972.

39 Idem. El destacado es nuestro.

40 El Rebelde, 1972b, op. cit, p. 7.

41 Enríquez, Miguel, Comisión Constituyente del Congreso de Unidad revolucionaria de la Vanguardia revolucionaria Marxista, 1965. En: Naranjo, P., Ahumada, M., Garcés, M. y Pinto, J. Miguel Enríquez, el proyecto revolucionario en Chile. Santiago, LOM, 2004, p. 42 La mayúscula es del original.

42 Enríquez, Miguel, “Congreso de Unidad Revolucionaria”, 1965, en Naranjo, et. al., op. cit., p. 19.

43 S/A, "Entrevista a Miguel”, en Punto Final, julio, 1969, p. 115.
} 
De hecho, en la práctica, en estas organizaciones de la nueva izquierda revolucionaria fue común que aquello contrario a la virilidad fuera desdeñado, por ejemplo, rechazando a aquellos hombres con deseos homosexuales, puesto que -se argüía- presentarían una mayor debilidad a la hora de resguardar información si se los tentaba sexualmente. Así, un ex mirista recuerda este comportamiento común dentro de estas organizaciones, cuando la homosexualidad entre varones era un tema tabú, y entre mujeres era totalmente invisible, señalando que:

habían (...) problemas de homosexualidad también. Y yo fui uno de los más ¿homofóbicos se diría ahora?, en ese momento. Porque dentro de mi evaluación estaba lo de qué pasa si se descubre eso en ciertas personas: el chantaje que harían los organismos de seguridad (...) podían generar problemas de seguridad... como cuando habían compañeros que... formaban dos o tres hogares distintos; era un problema que, además, iba en contra de los valores ${ }^{44}$.

La virilidad era un valor, mientras que la no-virilidad ejemplificada en la homosexualidad era un riesgo, un "problema", debilidad femenina que debía mantenerse a raya de la organización. La virilidad, era asociada -asimismo- con otras características vinculadas a la masculinidad hegemónica: la rudeza, la disciplina, la fortaleza, el valor. La idea, entonces, de sumar a las mujeres al proyecto de la revolución, quitándole con ello apoyo a las huestes reaccionarias, era integrarlas en términos de estas demandas militantes de masculinidad-virilidad que caracterizaban al revolucionario ejemplar y necesario para lograr el triunfo en la lucha.

\section{Las dificultades para "estar a la altura"}

Si bien en estos documentos producidos durante la Unidad Popular y previos al Golpe de Estado se las convocaba, la noción de que ellas se convirtieran en "un soldado más", no contemplaba que estas aspirantes a soldados accedieran a los mismos espacios de poder que sus pares varones. Una cosa es que ellas participaran en las bases -y hasta los mandos medios-, otra que determinaran los destinos de la organización.

Esta premisa no expresada, se evidenció en la práctica del MIR, siendo muy pocas quienes alcanzaron cargos en el Comité Central (CC) -la mayoría después que la represión aumentó la necesidad de nuevas jefaturas-, y ninguna a la Comisión Política (CP), órgano directivo superior, según revelan los registros documentales y testimoniales, así como la bibliografía especializada.

Antes del Golpe, las mujeres que tuvieron mayor autoridad -llegando a ocupar puestos en el regional Santiago- fueron la periodista Gladys Díaz, Lumi Videla ${ }^{45}$ y Marcia Merino ${ }^{46}$; además de María Isabel Matamala, quien en ese tiempo llegó a ser encargada del regional de Valdivia.

Poco antes del Golpe y fundamentalmente tras éste, y producto del recambio requerido por la represión, más mujeres asumieron estos puestos, ya fuera en Chile o en el extranjero, aunque siempre en franca minoría respecto de sus compañeros varones.

De ellas, dos ascendieron al CC post golpe: la periodista Gladys Díaz y la médica María Isabel Matamala, quienes ejercieron este cargo fundamentalmente fuera de Chile; mientras que en el CC

\footnotetext{
44 Carlos en López, Beatriz, ;Pueblo, conciencia, fusil, MIR, MIR! Representaciones y construcciones de masculinidad/ es como eje de identidad. Movimiento de Irquierda Revolucionaria, MIR:1967-1974. Tesis para optar al grado de Licenciada en Historia. Universidad Diego Portales, Santiago, 2010.

45 Lumi Videla fue ejecutada en 1974 y su cuerpo fue arrojado a la embajada italiana buscando hacer un montaje de su asesinato.

46 Marcia Merino fue detenida y llevada al cuartel de tortura Villa Grimaldi donde entregó información a los aparatos de inteligencia, razón por la que fue sindicada de traidora por el MIR y condenada a muerte. Tras ello se mantuvo vinculada a los organismos represores hasta que publicó su libro "Mi verdad", entregando información sobre el destino de militantes detenidos desaparecidos y ejecutados a la justicia.
} 
nacional hay menos claridad respecto de quienes ocuparon esta posición, aunque se sabe de Lucía Sepúlveda y Patricia Bravo, ambas periodistas, así como la monja católica Blanca Rengifo, fundadora del CODEPU. Resulta relevante, entonces, conocer de los testimonios de tres de estas mujeres dirigentas quienes lograron ingresar a espacios dominados cuantitativa y cualitativamente por varones, cómo fue la militancia desde este lugar negado para la mayoría de las militantes miristas. Gladys Díaz, una de las pocas que integró el CC, y quien ya era renombrada dirigente del Frente de Trabajadores revolucionarios (FTR) durante la Unidad Popular de Salvador Allende, relata que cómo fue una profesional del partido y aun así: "nunca me asignaron un sueldo y siempre tuve que estar lista para partir pa' cualquier lado, y qué sé yo, y... y eso jamás lo habrían hecho con un hombre. Se reían "no flaca, todo el mundo te admira, todo el mundo no sé qué... pídeles plata, si te van a dar"' 47.

Las diferencias se daban en el trato y también en el esfuerzo necesario para llegar y mantenerse en esos espacios que, para esta militante, eran más difíciles para las mujeres, puesto que "había que ser mucho más que el hombre ¿no?, eso, eso yo lo vi en todo, (...) yo vi ascender compañeros digamos, que, que al lado de ellos, a veces sus esposas mismas, sus parejas, eran mucho mejores" 48 .

María Isabel Matamala, quien también integró este espacio dirigencial durante la resistencia a la dictadura, coincide respecto de que "en las reuniones del CC, (...) nunca, nunca te, te daban como la misma importancia" 49 . Y, de hecho, en la escuela de guerrilla realizada en Cuba, y siendo la segunda al mando, recuerda un episodio en el que notó la resistencia por parte de los compañeros ante su autoridad, cuando el jefe político debió ausentarse:

Yo era la segunda, y entonces, (...) dormíamos todos juntos, hombres y mujeres en unos tremendos barracones con, con litera, entonces todas las mañanas el jefe, gritaba '¡de pie!', y entonces todo el mundo ipum!, se tiraba abajo y teníamos que salir a correr, y qué sé yo, pero nadie dudaba, todo el mundo estaba ahí. Y, bueno, y la primera vez que éste va a una reunión, y entonces yo tengo que asumir la comandancia yo grito 'ide pie!', y se levantan diez (...) Éramos como más de cien ${ }^{50}$.

En otra ocasión recuerda una importante reunión con un dirigente izquierdista centroamericano, para la que fue designada como representante del partido. De camino al evento se encontró con otro líder mirista del CC, quien paseaba con sus hijos y le preguntó si podía acompañarla, a lo que ella asintió indicándole que debía permanecer callado escuchando.

Al llegar, el dirigente centroamericano los hizo entrar indicándoles un lugar donde podían jugar los niños, comenzando la reunión con la María Isabel interviniendo. Tras unos minutos, el anfitrión la detiene señalándole: "momentito compañera, sabe qué, no me puedo concentrar con usted, porque cuando usted llegó yo creí que usted era la esposa de él, y que se iba a quedar con los niñitos viendo la televisión, y entonces yo nunca he hablado, nunca he mantenido relaciones políticas con una mujer, y pa' mi es muy difícil escucharla" ${ }_{51}$.

Con esta historia se evidencia que, a pesar de la bajísima representación de mujeres en puestos de autoridad mirista, esta situación era todavía más desigual en otras organizaciones de la Nueva Izquierda Revolucionaria latinoamericana, que ni siquiera acostumbraban a relacionarse con mujeres en espacios de liderazgo.

Lucía Sepúlveda, señala que ingresó al CC nacional luego de su asesinato de Augusto Carmona en diciembre de 1977, quien era pareja de ella y miembro de este nivel directivo, en una especie de reemplazo permanente dado por el grado de conocimiento que ella tenía de las labores del periodista.

\footnotetext{
47 Díaz, Gladys, 15 de enero de 2014, comunicación personal.

48 Idem.

${ }^{49}$ Matamala, María Isabel, 20 de noviembre de 2013, comunicación personal.

${ }^{50}$ Idem.

${ }^{51}$ Idem.
} 
En su caso, también señala haberse sentido menos respetada que sus compañeros, recordando que: "yo hacía mis intervenciones ya sea por escrito o en las reuniones (...) pero nunca nadie me inflaba y ahí yo sentía un poco que a lo mejor era porque era mujer, pero no estaba muy segura, siempre me quedé con la duda y me sentí subvalorada como dirigente por el colectivo" 52 .

Para la militante Ángeles Álvarez, esta desigualdad en las posibilidades de asumir jefaturas era una constante en la organización, señalando que aunque tenían los mismos deberes, la diferencia se daba en el plano de los derechos porque siempre "los hombres podían ser jefes de departamentos por ejemplo y tú te sacabas la cresta en un campamento y no accedías nunca a un cargo, y eso que los cabros chicos te querían, las pobladoras te pedían cualquier cantidad de cosas, pero (....) los primeros seleccionados eran hombres, nosotros partimos mucho después" 53 .

En el caso de jefaturas intermedias, era relevante demostrar que se podía ser tan duras y capaces como las dirigencias masculinas, para que no fuera puesta en duda la autoridad. Así, una ex militante recuerda que en esta militancia "uno tiene que ser riguroso, tiene que ser disciplinado, tiene que ser duro. Porque tú después vas formando a otras generaciones (...) cuando a mí me tocó ser jefe, yo era como mis jefes fueron conmigo" 54 .

En este testimonio, es reiterado el uso del masculino para hablar de sí misma en calidad de jefa, como si la manera en la que se debe actuar riguroso, disciplinado, duro, solo fuera posible desde la masculinidad o la impronta de ésta, en el caso de las mujeres.

Soledad Aránguiz recuerda cuando le tocó ser jefa de una escuela de guerrilla en Cuba, previo a la Operación Retorno a fines de los setenta, cargo inusual para una mujer que le habría tocado porque "era una escuela chiquitita". Y que por ello debió probar constantemente que, aun siendo mujer tenía lo suficiente como para merecer no sólo estar ahí, sino también ser una autoridad partidaria, tal como señala:

La gimnasia, el tipo de ejercicio que había que hacer, imagínate empezar a aprender kárate, y yo qué iba a estar haciendo kárate, si nunca me gustó ni me interesó, y tienes que aprender y ser buena. En tus prácticas, en las pruebas, tenías que ser bien aprobada, tales tareas para la próxima semana, aprenderse tales pasos, y uno ahí haciendo los pasos para aprendérselos, y si algunos a lo mejor necesitaban cinco sesiones para aprendérselos, otros a lo mejor íbamos a necesitar veinte. Y tenía que hacer las veinte para poder estar más o menos al nivel que se requería. Y esto de correr, imagínate yo al principio, no corría nada, después pensaba que tenía que ser capaz, y eran horas corriendo, y después corriendo con el uniforme, como mochilas cargadas a las tres de la tarde, o sea, cosas terribles, de las cuáles la mujer está muy distante. Una como mujer tiene otro tipo de sacrificios en la vida: las guaguas, amamantar, pero no ese tipo de cosas, y esto que te pasan un arma y tienes que aprender a usarla, aunque te dé miedo, porque (...) a su vez lo contrario provoca anticuerpos de los compañeros ${ }^{55}$.

En este relato, se evidencia la contradicción entre asumir que existían diferencias de condiciones entre hombres y mujeres que las ubicaban a ellas en desventaja en espacios como la Escuela de Guerrilla, y -al mismo tiempo- el intento de asimilación a las destrezas de los compañeros.

A esto se añadía que, además, cuando lograban equipararse a ellos, muchas veces el esfuerzo provocaba recelo en algunos pares varones, como recuerda Miryam Ortega respecto de su propia experiencia en la instrucción realizada en Cuba, señalando que "los chilenos son bien machistas, (...)

\footnotetext{
52 Sepúlveda, Lucía, 11 de diciembre de 2013, comunicación personal.

53 Álvarez, Ángeles, 2 de julio de 2014, comunicación personal.

${ }_{54}$ Cecilia en López, op. cit.

55 Aránguiz, Soledad, 26 de octubre de 2002, comunicación personal.
} 
cuando las mujeres les alcanzábamos las metas, les molestaba un poco, yo creo que les cuesta eso, competir con las mujeres en terrenos que son completamente masculinos, históricos". ${ }^{56}$

La exigencia de cumplir con características asociadas a la masculinidad para ser un buen combatiente, aun siendo mujer, se evidencia en el testimonio de Arinda Ojeda, quien recuerda las reacciones de la militancia mirista cuando -a mediados de los ochenta y estando prisionera- publicó su libro de poesía Mi rebeldía es vivir. En este texto hubo poemas catalogados de eróticos, por lo que no fue bien recibido, existiendo "una crítica a que reivindicáramos el derecho al amor y a enamorarse incluso estando presas. Eso era chocante. Se nos pedía ser militante, duras y guerreras. Como que la guerrera no puede amar" 57 .

Así, y ya casi en el último periodo de la historia de esta organización, continuaba vigente el mandato partidario de obviar lo personal. Y qué más personal que el eros de la feminidad anclado en cuerpos deseantes y que en la militancia debían ser neutralizados, con el objetivo de potenciar la entrega total a una masa colectiva homogénea y abstracta que impulsaría la revolución.

Para la dirigenta María Isabel existió en el MIR una presión cultural para que "la mujer mirista se asemejara a los hombres, (...) de alguna manera la influencia patriarcal, digamos, cruzaba incluso la noción de libertad, y de derecho a decidir, digamos, de las mujeres, era como... ser igual a ellos, ser igual" 58 .

En este anhelo de "ser igual a ellos", el objetivo era replicar el modelo del mejor, personificado en líderes del MIR como Miguel Enríquez o Bautista Van Schouwen, y sobre todo encarnado en el revolucionario latinoamericano por excelencia, el Che Guevara.

El modelo, por tanto, para mujeres y hombres es un mismo personaje masculino, ideal que para ellas resulta más complejo de imitar solo porque pertenece a otro espacio sexo genérico, lo que implica un salto cualitativo mayor. Mujeres imitando a un hombre, emulación posible con la repetición de actos cotidianos performáticos que las acercaran a esa masculinidad idealizada del revolucionario ejemplar. Dejar los estudios, la familia de origen, la ciudad de crianza, el país, la pareja y hasta los hijos. $\mathrm{El}$ abandono constante de todos los afectos y seguridades. Tomar un arma en las manos, armarla y desarmarla, cargarla en un bolso, poner una bomba, correr con una mochila de campaña a cuestas. Aprender a manejarse en espacios nuevos y desconocidos para la feminidad dominante. Reiteración de actos que dejaron de ser excepcionales para convertirse en la cotidianidad militante, es lo que finalmente las convierte de mujeres madresposas en combatientes.

El tránsito, entonces, desde el lugar asignado a la feminidad habitual, hacia el guerrillero -lugar anhelado pero desconocido- les permitió habitar ese espacio ajeno, aunque siempre en calidad de extranjeras, noción que para Lagarde describe la situación de mujeres en espacios masculinos "donde recibimos el trato de extranjeras incómodas con xenofobia de género" 59 .

Eso implicó que, a pesar de estar dentro, hubo una exigencia sistemática de demostrar que se tenía lo suficiente como para ser aceptadas en la cofradía, y que para moverse era necesaria una especie de visa que legitimara la participación femenina en estos espacios. Este permiso se vinculó con una suerte de masculinización, en la que las militantes debían asumir comportamientos que el sistema sexo género hegemónico mandata para los varones: arrojo, heroísmo, dureza, fuerza, frialdad, racionalidad.

Para habitar, aun momentáneamente, este espacio ajeno, ellas debieron probar que podían neutralizarse y borrar las diferencias a pesar del sexo de nacimiento y el género de la socialización; puesto que la incorporación a la orgánica requería, como señala Soledad refiriéndose a la Escuela de Guerrilla en Cuba: "meterme al mundo de los hombres y competir con ellos, no llegar a ser físicamente como ellos, porque eso ya es mucho pedir, pero sí hacer un gran esfuerzo por estar a la altura ‘ 60 .

\footnotetext{
56 Ortega, Myriam, 6 de febrero de 2014, comunicación personal.

57 Ojeda, Arinda, 16 de noviembre de 2002, comunicación personal.

58 Matamala, op. cit. El destacado es nuestro.

${ }^{59}$ Lagarde, op. cit., p. 393.

${ }^{60}$ Aránguiz, op. cit.
} 
"Estar a la altura", evidencia el deseo de asimilarse a los compañeros, en este caso en capacidad física, con el anhelo de pertenecer, "ser un soldado más" en esta cofradía de los mejores que liderarían la revolución social.

En espacios excepcionales como la Escuela de Guerrilla de fines de los setenta -sin el cuidado de los hijos ni las tareas domésticas de una familia- efectivamente se lograron espacios de igualdad en los que hombres y algunas mujeres parecieron asimilarse momentáneamente. Igualdad lograda con el esfuerzo extra que ellas debieron realizar para "estar a la altura" de compañeros que de niños habían jugado a la guerra, mientras ellas eran preparadas por la sociedad con juegos de crianza y labores de cuidado.

La pretendida igualdad, espejismo de neutralidad militante, -sin embargo- se fracturaba cada vez que ellas debieron optar entre los requerimientos del adentro y las exigencias del afuera, evidenciando que para lograrlo debían realizar sacrificios en mayor medida que sus compañeros de organización, como dejar a los hijos e hijas al igual que sus compañeros y al mismo tiempo ser más cuestionadas por esto tras la derrota del proyecto revolucionario ${ }^{61}$. Una de estas diferencias evidentes, y que muestran la dificultad de ver incluso desigualdades en el plano físico, el relato de la militante Miryam Ortega, quien recuerda que a las mujeres en la escuela de guerrilla en Cuba les costaba asumir sus limitaciones físicas: "entonces a la hora de preparar las mochilas, las primeras veces que fuimos de campaña, preparamos las mochilas como todo el mundo, pero resulta que después no las podíamos levantar, porque está muy pesada, [entonces ahí] también dijeron: '¿cuánto pesas tú?, no puedes cargar más de un tercio de tu peso"62.

Para Arinda, la exigencia de demostrar que se tenía lo suficiente era constante y se evidenció en momentos claves como la decisión de unirse a la Operación Retorno que implicaba prepararse militarmente y retornar clandestinamente a Chile, momento en el que ella -así como muchas otrasdebió decidir dejar a su hijo, una de las decisiones que recuerdan más difíciles en los testimonios recogidos: "cuando se venía un compadre a Chile, atrás quedaba una mujer haciéndole señas y un cabro chico agarrado a la falda gritando por su papito. Y cuando se venía uno nadie consolaba el cabro chico y además había que hacerse un lugar donde volver ${ }^{63}$.

Esta diferencia era obviada en este intento de equipararse a los compañeros, puesto que, si se era mujer militante, recuerda Arinda: "había que demostrar porqué se venía. Nadie nos decía que debíamos ponernos 10 kilos más en la mochila, pero había que hacerlo para demostrar porque una se venía" 64 .

En este mismo sentido una militante recuerda que la posibilidad era elegir el tipo de militancia que se tendría, "porque tenías que ser militante, pero asimilándote a un rol masculino, privándote de tu derecho a ser mujer, o eras mujer de verdad y tomabas tareas de ayuda, de retaguardia" 65 . El testimonio da cuenta de una opción dicotómica de militancia cuyas alternativas eran reproducir lo femenino hegemónico -con menor prestigio- o acceder a la masculinidad hegemónica -con un prestigio mayor-.

Carmen Castillo, quien fue mirista y pareja del máximo dirigente que tuvo esta organización, plantea que esta pretendida igualdad basada en neutralizar las diferencias de condiciones fue resultado de que la pregunta por las especificidades femeninas era escasa e incipiente en la primera época del MIR, recordando las miristas no se planteaban "la cuestión de si éramos mujeres y militantes, todos éramos militantes: hombres, mujeres, jóvenes, obreros, campesinos, indígenas, etc. La especificidad de lo que implicaba ser mujer vino mucho más tarde" ${ }^{66}$. Así, la máxima lingüística lo que no se nombra no

${ }^{61}$ Vidaurrázaga, Tamara, "Subjetividades sexo genéricas en mujeres militantes de organizaciones político-militares de izquierda en el Cono Sur”, La Ventana, 41, enero-junio, Guadalajara, 2015.

62 Ortega, op. cit.

63 Ojeda, op. cit.

${ }^{64}$ Idem.

${ }^{65}$ Rebeca en López, op. cit.

66 Ghio, Bettina y Di Piero, Norma, "Dar al término 'mujer comprometida' toda su amplitud poética”, entrevista a Carmen Castillo, 2013. 
existe, explicaría esta limitación para asumir una diferencia que en la práctica cotidiana militante se evidenciaba recurrentemente.

\section{La neutralización de las improntas}

Varios testimonios recuerdan cómo las miristas no solo cambiaban su accionar, sino también sus improntas, con el fin de neutralizar rasgos de aquella feminidad que las ubicaba en desventaja para acceder al lugar anhelado del guerrillero dentro de la organización. Para esto, la indumentaria, accesorio fundamental en la expresión de la feminidad hegemónica, era utilizada para representar el papel de la militante ejemplar que no perdía tiempo ni dinero en banalidades.

Ángeles Álvarez describe una especie de traje militante en su época universitaria y de trabajo poblacional durante la Unidad Popular, compuesto de la siguiente manera: "el blue jean desgastado, (...) la zapatilla que no te comprabas para que fuera vieja, era la bolsa de telar que te colgaba acá, en lo posible cero maquillaje y nada de aritos de oro o cositas por el estilo (...) eso era lo que el MIR nos exigía"67.

El testimonio de Eva Palominos revela haber sido amonestada durante el mismo periodo previo a la dictadura por repartir El Rebelde en una fábrica vestida coquetamente, cuestión que su jefe consideró “(...) era contraria a la vocación y al accionar revolucionario", siendo "conminada a permutar las minifaldas por los jeans en la realización de las tareas partidarias (...) en el pasaje al frente sindical tuve que abandonar rápidamente las tenidas de estudiantes en polleras cortas" 68 .

En ambos casos, el mandato era la austeridad de la indumentaria, transformando así el uniforme de la moda femenina de los setenta, en otro uniforme que debía emularse rígidamente, el de la revolucionaria, puesto que en caso contrario se corría el riesgo de ser catalogada de pequeño burguesa, evidenciando que la molesta feminidad era una huella necesaria de intentar borrar. Esta neutralización que implicaba abandonar los rasgos que evidenciaban la especificidad femenina se traducía, según el recuerdo de Alejandra, en que "teníamos que ser muy achorá... despreocupada de la... del hermoseamiento (...) yo no recuerdo que ninguna compañera se pintara". Ello no se recuerda solo como una opción, sino también una expectativa para quienes militaban en una organización revolucionaria y guevarista, mujeres que en general eran "poco femeninas y se esperaba que no lo fuéramos mucho" 69 .

Para Soledad, a inicios de los setenta, y todavía en democracia, cuando era estudianta secundaria: "éramos como una repetición de la María Isabel Joui, hasta en la ropa, porque ella usaba ropa como de batalla: parka, blue jeans rectos, en vez de patas de elefantes, bototos. Era como anti moda, y nosotros nos vestíamos igual, porque al igual que ahora la ropa era muy importante para lo que queríamos decir"'70.

El uniforme de revolucionaria entonces, pasó a ser un accesorio requerido en este tránsito suerte de mujer a guerrillero, que contemplaba no solo abandono de actitudes y represión de deseos, sino también transformación de la indumentaria.

Esta austeridad es algo que recuerda Lucía sobre cómo eran las miristas, quienes "se las arreglaban con pocas cosas para vivir y pa' vestirse, no sé, como que no se complicaban la vida por cuestiones, o sea, como sabiendo diferenciar lo esencial de lo accesorio"71.

Carmen también refiere a cómo se auto impuso una transformación estética con el fin de convencer a Miguel Enríquez de que podía ser la militante y compañera que él necesitaba a su lado: "No más minis, ni vestido gitano, ni sombreros, se acabó la provocación, tengo que lograr convencerlo

\footnotetext{
67 Álvarez, op. cit.

68 Palominos, Eva, Vuelo de Mariposa, una Historia de amor en el MIR, Santiago, Escaparate, 2007, p. 55.

${ }^{69}$ Alejandra, 13 de diciembre, comunicación personal.

70 Aránguiz, op. cit.

${ }^{71}$ Sepúlveda, op. cit.
} 
algún día de que soy capaz de discreción y sencillez"72. La performance de esa otra que quería llegar a ser, la militante dura, austera y aguerrida, se evidencia con la meta respecto del abandono de la coquetería, tara femenina.

Esta militante relata cómo Lumi Videla (llamada Luisa en el relato, por su nombre político) una de las pocas mujeres que lideraba el regional Santiago a inicios de la dictadura- representaba ese canon ideal de mujer mirista, describiéndola de la siguiente manera:

\begin{abstract}
Luisa se convirtió, sin haberlo buscado ni pedido, en la encarnación de la militante ejemplar, de la mujer mirista (...) No se le conocía debilidad femenina alguna; era la mujer del Chico, uno de los dirigentes, pero no era eso lo que contaba: Luisa existía por sí misma y era una de las dos mujeres del partido que en aquellos años tenían tareas de responsabilidad (...) Luisa, la imagen de la mujer segura de sí misma, consagrada por completo al combate político, jamás una grieta, siempre sin rodeos, nunca una excusa ${ }^{73}$.
\end{abstract}

Lumi era esa militante ejemplar que todas emulaban, porque no era "la mujer de", sino que había ganado sus espacios militantes por sí misma, pero sobre todo por su entrega "completa" a la causa sin "grietas ni excusas", en una consagración que se asimila a la entrega cristiana.

Lumi, la dura, la estoica, era lo contrario de Carmen, quien se auto reprimía para esconder su feminidad, tara en un contexto en donde las especificidades y lo suntuoso resultaban un retardo para los objetivos revolucionarios que requerían una masa homogénea de militantes, dicho a secas, subsumiendo las diferencias dentro de este colectivo.

Avanzado el texto de Castillo, se evidencia la otra cara de Lumi, esa que estaba auto negada para lograr autoridad entre tanto varón, cuando es observada en el cuartel de torturas Villa Grimaldi, donde: "Luisa rumiaba sus lágrimas en silencio, ellas también. Luisa se avergonzaba de sus penas, ellas también. Ambas habían concebido a Luisa como la dirigente pura y dura, símbolo de la militante intachable, pero Luisa era una mujer como las demás"74.

Así, la frase final resulta categórica: "era una mujer como las demás" implica que lo anterior era un disfraz que le permitía habitar espacios masculinos de poder, impronta requerida para hacerse respetar, demostrando que tenía lo suficiente; y para lo que debía esconder su debilidad expresada en lágrimas femeninas que evidenciaban la fragilidad escondida durante la militancia.

\title{
El desvanecimiento del velo de igualdad
}

Ni Lumi, ni las demás lograron transformarse permanentemente en las militantes duras y neutras que la militancia revolucionaria exigía, si no solamente por episodios en los que las excepcionalidades permitieron un "espejismo de igualdad" o "velo de igualdad"75 complejo de mantener de forma permanente.

A mayor excepción, mayor posibilidad de que este espejismo fuera posible, por ejemplo, en la Escuela de Guerrilla o durante la clandestinidad del retorno. Al contrario, a mayor cotidianidad, fue más posible la emergencia de malestares ante la evidencia de que la igualdad basada en una impronta supuestamente neutra era inviable, más aun, dejando intocado el plano de lo personal, familiar y doméstico. Así, momentos de menor excepcionalidad como el exilio o la cárcel -en que las mujeres además pudieron colectivizar sus tensiones y malestares- fueron espacios en que este espejismo se rompió.

\footnotetext{
72 Castillo, Carmen, Un día de octubre, Santiago, LOM, 2013, p. 120.

73 Castillo, op. cit., p. 45. El destacado es nuestro.

74 Ibid., p. 90.

${ }^{75}$ Lagarde, op. cit.
} 
La militante Patricia Zalaquett relata haber vivido una suerte de igualdad en el primer tiempo de su militancia, durante la Unidad Popular e inicio de la dictadura, puesto que "se me exigía igual y a veces más, bastante más, porque yo hacía todas esas cosas y las hacía sin mayor problema en el sentido de ser respetada como militante" 76 .

Este espejismo finalizó abruptamente cuando se emparejó con un militante con mayor responsabilidad, quien a inicios de los ochenta fue enviado como jefe político al trabajo de resistencia que se realizará en el sur de Chile.

En ese momento ella recuerda que: "el MIR busca que tú te transformes en la compañera solamente, la mujer, para poder resguardar todo lo demás, o sea, ahí yo sentí que mi experiencia no valía nada para los compañeros del MIR" "77. Así, la militante, relata cómo pasó de hacer un trabajo poblacional de masas muy valorado, a convertirse en la asistente de su pareja, labor invisible partidariamente y que desaprovechaba su experiencia política.

Para Marta esta situación era generalizada, recordando que si una militante "tenía un compañero que era de más alto nivel, en el fondo estaba al servicio del trabajo de él y de cuidarlo a él, podía tener sus propias tareas pero esas estaban totalmente supeditadas a las tareas de él"78.

Así, no era extraño que experiencias relevantes para la organización como las de Patricia, fueran subsumidas en las necesidades militantes y la seguridad de quien tenía la mayor autoridad partidaria dentro de la pareja, usualmente varones.

Una cuestión que se reitera en los testimonios es cómo la llegada de los hijos e hijas, y las necesidades de cuidado de éstos, fue detonante que evidenció la dificultad de esta igualdad pretendida, recayendo la responsabilidad mayormente en las madres, como sucedía en el resto de la sociedad. Así lo señala Alejandra respecto de lo que observó durante su militancia mantenida durante toda la dictadura:

\begin{abstract}
pa' mi los hijos marcaban la mayor diferencia, no era el ser pareja, sino el tener hijos, porque eso cuestionaba 'bueno, ¿Qué hacemos? ¿Cómo dividimos la pega con los hijos?', porque mientras se era pareja, yo creo que era menos complicado, porque nadie preparaba, a nadie le importaba como en eso, entonces, la pega doméstica la hacía el que podía, aunque se tendía a que la hicieran las mujeres, evidentemente, pero, pero no era mayor rollo, digamos, no era mayor rollo porque no era preocupación, pero a los niños tenis' que cuidarlos, tienes que darle tiempo y entonces ahí, ahí empezaban las crisis ${ }^{79}$.
\end{abstract}

A fines de los sesenta, y cuando el país se encontraba en democracia, algunos dirigentes del MIR ya estaban en clandestinidad, Carmen recuerda cómo era ser pareja de los dirigentes miristas y aun siendo todas ellas militantes, señalando que: "Andrés, Miguel, el Bauchi y los otros ya vivían clandestinos. Sus bebés, Camila, Pablo, hijo de Inés y del Bauchi, así como Javiera, la hija de Alejandra y Miguel, habían nacido entre julio y octubre, tenían todos entre seis y dos meses. Nosotras, las madres, vivíamos solas, cada una con su bebé, trabajábamos y cuidábamos a los niños" 80 .

Si bien la clandestinidad obligada de ellos era la razón que se daban estas mujeres para explicar el por qué ellas se debían hacer cargo de todas las necesidades prácticas de ellos, la desigualdad era evidente. Ellas trabajaban para tener dinero y mantenerse, cuidaban solas a bebés de menos de seis meses, y seguramente también se hacían cargo de las tareas partidarias de ellos en calidad de "asistentes", tan común en muchas parejas de dirigentes, subsumidas e invisibilidad as en los trabajos políticos de ellos.

\footnotetext{
76 Zalaquett, Patricia, 17 de enero de 2014, comunicación personal.

77 Idem.

78 Marta, 21 de julio de 2014, comunicación personal.

79 Alejandra, op. cit.

${ }^{80}$ Castillo, Carmen y Echeverría, Mónica, Santiago-París. El vuelo de la memoria, Santiago, LOM, 2002, p. 118.
} 
Esta desigualdad se mantuvo incluso cuando ambos estuvieron clandestinos, ya después del golpe de 1973, días en los que Carmen se hacía cargo de las múltiples tareas políticas de Miguel, siempre en calidad de asistente, y respecto de los que recuerda -llamándose a sí misma "Catita", que es como le decía cariñosamente Miguel-: "Con frecuencia él le reprocha: Catita, no tienes ninguna formación, actúas instintivamente, es insuficiente, ponte a trabajar en serio, no seas floja... Ella protesta, cómo quiere que estudie si no tiene tiempo con las tareas militantes, las niñas y el hogar y... sí, él" "1.

En esta frase, se evidencia lo que es común a todas las madresposas, las tareas de cuidado como un sin fin de deberes que no dejan tiempo ni tienen fin, tareas que incluyen el hogar, las niñas (de Carmen y de Miguel) y hasta el propio dirigente, quien es sumado a los deberes de cuidado de Carmen, como un niño más. $\mathrm{Y}$ a esto, se le añaden las tareas militantes que, aun subsumidas en las responsabilidades de él, son cuantiosas y de peligro.

Así, la militancia de Carmen no se realizaba posponiendo las tareas propias de la madresposa, sino sumándolas a la de la compañera militante, debiendo -además- convivir con la crítica e invisibilidad constante: desde su lugar de madresposa porque nunca las hijas ni la casa tendrían la atención necesaria, desde la militancia porque no tenía posibilidades de estar al nivel de Miguel, con dedicación total a la organización. La frase "no seas floja", es la evidencia de este reproche desde el lugar militante. "No seas floja", "sé como yo, que leo y estudio y me esfuerzo políticamente".

Lo que no está en la frase de Miguel es el reconocimiento a esas otras labores que Carmen realizaba a la par de la militancia y que subsidiaban el trabajo político de él, alivianado de las responsabilidades domésticas y de cuidado de su propia hija; desigualdad de sexo género que ella solo se atreve a enunciar años después, con la experiencia del exilio.

Para Patricia, la maternidad acentuó todavía más la secundariedad de su militancia, dado que con la llegada de la hija en común, quien requería cuidados ineludibles en medio de la clandestinidad de los ochenta post Operación Retorno, fue evidente que las exigencias de lo privado se cargaban en ella, señalando que "cuando uno es joven y no tiene hijos no importa a qué hora llegues a las casa, no importa si tienes que escribir un documento hasta las tres o cuatro de la mañana" 82.

Para Nubia Becker, quien militó desde antes de la dictadura hasta el final de esta, también fue la llegada de hijos e hijas el momento que más evidenció las desigualdades en la militancia de hombres y mujeres miristas, recordando que "no se compartía mucho en las mujeres que tenían hijos era el cuidado de los hijos con los hombres. No se compartía, yo creo que nada. Siempre la militancia de la mujer fue con hijo y la del hombre fue sin mujer y sin hijo" 83 .

Esta responsabilidad mayor para las mujeres, sobre todo en lo que respecta al cuidado de hijos o hijas, se evidencia en los testimonios sobre la vida clandestina pero también en el exilio, donde la emergencia y excepcionalidad disminuyeron y se vivió con mayores posibilidades de normalidad aún en un espacio ajeno.

Soledad recuerda cómo a la hora de ir a las reuniones había qué decidir cuál de los dos se quedaban con los niños y niñas, señalando que había miristas que "tenían dificultades para ir a las reuniones porque no tenían con quien dejar a los niños. Si hay un hombre y una mujer ¿quién va a la reunión? El hombre. Es un hecho que quien es la primera responsable por los niños es la mamá, entonces esas cosas igual se repetían afuera" 84 .

Arinda coincide en la prioridad masculina para la asistencia a reuniones en Europa, sobre todo las grandes; y para Nubia, el tema de los hijos siempre fue responsabilidad mayoritaria de las mujeres del MIR, señalando que "las mujeres siempre tenían que pensar cómo lo hago con los hijos, cómo lo hago para tener un trabajo, cómo lo hago para, pa... todas esas cosas, ¿no? (...) ahí se dio claro... por

\footnotetext{
81 Castillo, op. cit., p. 33. El destacado es nuestro.

82 Zalaquett, op. cit.

83 Becker, Nubia, 13 de diciembre de 2013, comunicación personal.

${ }^{84}$ Aránguiz, op. cit.
} 
eso te digo después yo me di cuenta que no era tan así la emancipación de la mujer en el MIR y, sobre todo lo veo hoy día más claro que nunca" 85 .

Esta opinión es compartida por otras militantes como Miryam, quien refiriéndose al tiempo de la Operación Retorno que comenzó a fines de los setenta, señala que en la práctica "las mujeres seguían teniendo triple, cuádruple carga, los compañeros iban a la lucha y las compañeras se quedaban con los hijos" $" 66$.

Soledad recuerda esta misma tensión en el exilio en Europa, especialmente cuando el MIR planteó la Operación Retorno a su militancia y la mayoría de quienes en una primera etapa regresaron al país clandestinamente fueron hombres, hasta que las mujeres criticaron esta situación increpando a la organización respecto de qué pasaba con ellas en este plan ${ }^{87}$. Así, surgió una demanda que las autoridades partidarias -mayoritariamente varones- no habían visto: el interés de las militantes en participar de este proyecto político y, al mismo tiempo, la necesidad de resolver el cuidado de los hijos e hijas que habían tenido en el exilio o antes, y que en general tenían muy corta edad. Sobre esto, la militante recuerda:

Esta primera parte de la política del retorno fue absolutamente machista, porque contemplaron que se iban a ir los puros hombres y que de repente alguna mujer, la más desafiante, la más agrandada se iba a ir, pero un caso lo podían resolver, llevan el niño a Cuba o lo dejan con un familiar. No pensaron que las mujeres iban a plantearse igual que los hombres. Ellos nos lo plantearon a todos, pero en lo concreto igual estaban dejando fuera a las mujeres porque no habían solucionado el tema de los hijos. Y cuando empezaron a desaparecer los hombres y quedaron las mujeres solas, como en Amberes, donde teníamos un clan súper fuerte de mujeres, y empezamos a preguntarnos '¿Y nosotras qué? ¿Los compadres se van un año a Cuba, se van a Chile y nosotras tenemos que esperar hasta que haya terminado todo, criamos a los hijos aquí y cuando todo haya terminado nos volvemos allá con ellos?'88.

Este momento de la militancia evidenció lo que ellas vivieron por años: se las convocaba y aceptaba en todos los espacios partidarios a cambio de que obviaran sus condiciones específicas, por ejemplo, ser madres. Con ello, si bien no se les impedía ser parte del retorno, en la práctica, había un impedimento concreto que significó que las primeras oleadas que regresaron a Chile en general fueron hombres o mujeres excepcionales que pudieron resolver de manera individual el cuidado de los infantes.

Cristina, quien también participó del retorno dejando a su hijo en el Proyecto Hogares en Cuba, recuerda igualmente que regresaron primero los varones, significando -en muchos casos- dejar a sus parejas a cargo de los hijos e hijas, quienes debieron resolver por su cuenta si se sumarían a esta política partidaria (dejando a los infantes al cuidado de otros) o se quedarían con los menores renunciando a militar profesionalmente ${ }^{89}$.

La Operación Retorno y la demanda por parte de las militantes de una solución partidaria, fue uno de los momentos en que se evidenció más notoriamente que hombres y mujeres del MIR tenían condiciones sexo-genéricas diferentes que no podían obviarse. No era posible retornar clandestinamente con los hijos e hijas, y si el cuidado de los menores no se resolvía orgánicamente, la responsabilidad en general recaía sobre las militantes madres, quienes a su vez no podían participar en la misma medida que sus compañeros.

\footnotetext{
85 Becker, op. cit.

86 Ortega, op. cit.

87 Vidarrázaga, 2006, op. cit.; Aguiló, Macarena, El edificio de los chilenos, 2010.

88 Aránguiz, op. cit.

${ }^{89}$ Chacaltana, Cristina, 22 de febrero de 2003, comunicación personal.
} 
Tras la demanda de las miristas que estaban en distintos países del exilio Europeo, la dirigencia resolvió organizar un espacio de crianza colectiva en Cuba llamado Proyecto Hogares, en el que se determinó dejar a niños y niñas al cuidado de "padres sociales", hombres y mujeres que hacían esta tarea como parte de sus labores militantes ${ }^{90}$.

Algunas de las retornadas dejaron a sus hijos e hijas en esta especie de guardería mirista, otras, a cargo de familiares o personas cercanas en Cuba, Chile u otros países, y otras, decidieron quedarse criando. Para todas las que fueron parte de este debate, un tema central fue que la inclusión de ellas en esta etapa de la lucha requería resolver previamente el cuidado de los "hijos e hijas del partido". Se evidenció, así, que el espejismo de igualdad -que algunas conservaban hasta entonces- no era posible, toda vez que eran mujeres incardinadas, con condiciones y socialización femeninas en una sociedad patriarcal, y no revolucionarios neutros, como se pretendía en la noción de "hacer de cada mujer un soldado más".

\section{De la madresposa al guerrillero}

Estas militantes evidenciaron una transgresión radical a los mandatos sexo genéricos hegemónicos, al militar en una organización político militar, huyendo así del cautiverio de la madresposa. Al mismo tiempo, la inclusión de ellas en la orgánica se realizó asumiendo que eran combatientes neutros, negando con ello las condiciones devenida de los mandatos de género y sus socializaciones en la feminidad dominante, lo que pudo sostenerse en ciertos períodos, pero constantemente resultó en malestares que evidenciaron la desigualdad. Ello, porque para la orgánica las tareas devenidas de lo privado y lo individual, aquellas "cosas sin importancia", tenían un menor valor que aquellas vinculadas a lo público y colectivo, lugar de la revolución por venir.

Los testimonios revelan satisfacción por el proyecto elegido en libertad: la militancia y la lucha político y armada por la revolución socialista, los tiempos del afuera. Y al mismo tiempo evidencian culpas por el incumplimiento de las expectativas sociales, familiares, aquellas demandas -pero también deseos- del adentro, como las maternidades.

Así, Patricia reflexiona respecto de la militancias de las miristas señalando que "a las mujeres se les exigió dejar de ser madres y mujeres y convertirse en militante, o sea, no hay una política de familia respecto a eso, la solución del proyecto hogares es nefasta". ${ }^{91}$ Estos malestares fueron más o menos visibles durante la militancia, acentuándose con el paso de los años y el fin de la emergencia, cuando lo personal las asaltó como demanda ya fuera desde los otros o desde sí mismas, momento en que la apuesta colectiva y pública de la revolución resultó derrotada. Si bien hubo momentos en que el espejismo de igualdad las hizo sentir parte, como "un soldado más", la mayoría de los testimonios revelan que el tiempo evidenció la imposibilidad de ser parte del nuevo lugar del guerrillero a la par de sus compañeros.

La militante Rebeca, sintetiza muy bien esta tensión en el tránsito desde un lugar a otro, señalando que "normalmente yo sentía una sobre exigencia, una culpa muy grande, porque el deber ser era de hombre militante: racional, rápido para tomar decisiones; y uno tenía toda una manera de ser y vivir que eran de mujer, de mujer militante (...) entonces yo me decía 'me tengo que superar, tengo que ser más firme"'92.

En esta frase, "ser más firme" se contrapone a la supuesta debilidad femenina, y "me tengo que superar" alude a las taras de la feminidad mal recibidas en un escenario de lucha política y militar, que justamente requería características asociadas con la masculinidad hegemónica: racionalidad, frialdad,

\footnotetext{
90 Aguiló, op. cit:; Vidaurrázaga, Tamara. "Pequeños compañeritos: Los hijos del MIR y Montoneros en los hogares colectivos de Cuba" en Exilios del cono sur: género, generación y clases, Jimena Alonso, María Eugenia Horvitz y Carla Peñaloza, Santiago, Cuarto Propio, 2018, en prensa.

91 Zalaquett, op. cit.

92 Rebeca en López, op. cit.
} 
asertividad, virilidad, en palabras de Miguel Enríquez. Ser y comportarse como una mujer eran una carga que Rebeca intentaba esconder para asemejarse al ideal que era de hombre militante, cuestión a la que -por supuesto- no tenía posibilidades de llegar realmente, evidenciándose la dificultad para habitar ese lugar desconocido y ajeno que requería el disfraz de la masculinidad.

Esta noción de no hallar un lugar propio en este recorrido desde la madresposa hacia el guerrillero, se evidencia en una entrevista de Carmen Castillo en la que la militante señala:

\begin{abstract}
Quise denunciar en ese momento de la película la mascarada de la mujer militante y libre de sus responsabilidades, que no existe. No se puede ser militante y mujer más que en el día a día y allí donde no se está. Es ésta la cuestión que más me interesa de la acción y del pensamiento. Creo que perfectamente se puede ser mujer y militante en todo momento, que se trata simplemente de desmitificar la mujer militante, volverla "normal", porque de lo contrario querrá decir que es excepcional y que sólo las gentes excepcionales pueden ser militantes y mantenerse fieles a una organización ${ }^{93}$.
\end{abstract}

Resulta relevante la reflexión respecto de que ser militante y mujer -roles contradictorios según este testimonio, en las condiciones en que ella lo vivió- es algo que se vive cotidianamente, "allí donde no se está". O sea, en todos los lugares en los que se estuvo en falta por la opción momentáneamente tomada: en la reunión a la que no se asistió por tener al hijo con neumonía faltando como militante, en la cotidianidad del hijo al que no se le narró un cuento nocturno por haber estado en tareas militantes. La huida de estas militantes desde el lugar mandatado y conocido de la madresposa hasta el combatiente -dicho a propósito en masculino- significó un tránsito inacabado, porque termina en un lugar masculino en términos culturales e históricos, donde no existen certezas puesto que ya se comenzó un viaje hacia territorio ajeno.

Si bien lograron habitar este nuevo espacio, lo hicieron en calidad de extranjeras, constantemente bajo sospecha de tener lo suficiente para compartir ese espacio. Por más que respetaran todas las reglas exigidas por la militancia, siempre estarían en falta. En el lugar del guerrillero, porque no cumplían con las demandas y deseos de la madresposa. En el lugar de madresposas, porque las exigencias de este rol no les permitían ser buenos guerrilleros. La guerrillera nunca es igual al guerrillero, por más que así lo crea temporalmente, se halla entre la feminidad fallida, referida por Lagarde, y la masculinidad fallida, en ninguna se encuentra a gusto totalmente, en ninguna logra ser parte y en ambas quedará en deuda, sin posibilidades de hallarse. Así, estas mujeres habitan un No Lugar sexo genéricamente hablando, puesto que -estuvieran donde estuvieran- el sino de estas mujeres devenidas en guerrilleros, era justamente no estar en algún lugar, siendo evaluadas y auto evaluándose por sus faltas, cuestión que para muchas de las testimoniantes fue un peso con el que han continuado viviendo muchos años después de abandonar la militancia partidista.

\title{
Algunas ideas finales
}

El MIR, en consonancia con las organizaciones de la Nueva Izquierda Revolucionaria latinoamericana, reprodujo la herencia patriarcal liberal, relevando lo público por sobre lo privado. Con ello se subestimó el potencial transformador de las experiencias de participación surgidas a partir de tensiones en la esfera de la "reproducción", reconociendo como únicamente válidas -y propias de un proyecto histórico y político emancipador- aquellas demandas vinculadas al ámbito de la producción y a las contradicciones de clase.

Si bien el proyecto de la revolución social fue una elección vivida en libertad y en parte con satisfacción, al mismo tiempo las exigencias de organizaciones político militares -como el MIR chileno-

${ }_{93}$ Ghio y Di Piero, op. cit. 
implicaron que las energías de estas militantes fueron todas puestas en lo público y lo colectivo, con escasas posibilidades para desarrollarse personalmente, ya que lo privado e individual se comprendió como una traición al proyecto principal, la lucha revolucionaria.

Estas mujeres, entonces, ingresaron a espacios que históricamente les habían sido negados -lo político y lo militar, cofradías masculinas- y en los que se les exigió comportarse escindidamente, dejando en un lugar secundario justamente aquello para lo que habían sido socializadas primordialmente: lo individual, lo privado, lo concreto del mundo familiar y doméstico.

Así, aunque lo privado, lo individual, la concretitud de lo doméstico fueron los terrenos para los cuales habían sido socializadas, la militancia les exigió enfocarse casi completamente en lo público, lo colectivo, la abstracción del proyecto revolucionario. Estas escisiones fueron vividas con gran dificultad por personas de carne y hueso con preocupaciones, deseos, responsabilidades y proyectos individuales y privados, especialmente para las mujeres, quienes transgredieron sus mandatos sexo genéricos de manera notable.

En los testimonios de estas mujeres, quizás por el hecho mismo de ser humanas socializadas para remitirse a la concretitud de la esfera de lo privado, es evidente esta falsa dicotomía, evidenciando cómo las exigencias de lo público afectaron lo privado, a la vez que las privadas tensionaron las públicas, y cómo el mandato de colectivización radical fue imposible, por más que entonces la búsqueda de individualidad se leyera como una tara burguesa de la que era necesario desprenderse.

La incorporación de estas mujeres en la organización, sin tener en cuenta las condiciones, los mandatos y los deseos a partir de lo sexo-genérico, implicó que se las reclutó exigiéndoles actuaciones que parecieron neutras pero que se vinculaban con la masculinidad hegemónica, haciéndoles más difícil la militancia, y acarreándoles mayores costos que a sus compañeros varones. Fueron aceptadas en un espacio masculino, la cofradía, pero a cambio debieron despojarse de todos sus ropajes femeninos, que -en la esfera de lo político público- fueron vistos como lacras molestas y contrarrevolucionarias.

La militante, en este caso, o sea la mujer libre devenida en guerrillero, funcionó entonces como una mascarada, disfraz que pudo utilizarse a ratos, pero no mantenerse de por vida, porque no era parte de la piel propia, sino indumentaria extraña y prestada solo a momentos. No importó entonces lo que se exigía como ofrenda para pertenecer a la secta política, ni cuánto dolor causara obedecer los mandatos sacrificiales: si querían demostrar que -a pesar de ser mujeres- podían dar tanto como sus pares varones, debían ser capaces de sobreponerse a sus habitualidades, a los mandatos bajo los que habían sido criadas, a los amores cercanos y concretos, al anhelo de proteger a los suyos antes que a la humanidad.

Así, debieron ofrendar el cuerpo del deseo, tan propio de lo femenino y de las mujeres, hegemónicamente hablando; para demostrar que estaban dispuestas a dejar sus individualidades y espacios privados con el fin de ingresar al cuerpo de lo político, lugar de lo colectivo y lo público, como señala Schmucler' ${ }^{94}$.

Tal como señala el autor, la revolución finalmente se transformó en ese monstruo que al devorar el cuerpo del deseo y a los individuos que luchaban por ella95, devoró también toda posibilidad de singularidad que no calzara con la homogeneidad requerida, que respondía al guerrero-héroe, siempre en masculino. Devoró también a las mujeres, a las diversidades sexuales, a las especificidades étnicas y raciales, a las diferencias etarias. Así, fue borrado cualquier rasgo que sobresaliera en ese colectivo público, que como enjambre se movía de un lugar a otro haciendo la revolución con seres despojados de sus singularidades, transformados en enjambres revolucionarios con pensamiento colectivo, puesto que, como bien señala la filósofa argentina Alejandra Ciriza, leyendo a Schmucler, la revolución "concebida como una meta abstracta, como un fin sin que interesaran los medios, contribuyó al borramiento de la percepción de las consecuencias psíquicas y políticas de las diferencias

\footnotetext{
${ }^{94}$ Schmucler, Héctor, “Testimonio de los sobrevivientes”. Controversia, 9-10, 1980.

${ }^{95}$ Idem.
} 
entre los cuerpos sexuados, a suprimir en aras del ideal todo aquello que fuera obstáculo a la determinación de continuar, incluida la propia subjetividad" 96 .

Existió, entonces, una diferencia entre haber militado en una organización político-militar como el MIR habiendo sido varones o mujeres. Primero, porque lo que no se nombra no existe, por tanto, la idea de militancia neutra se vivió por parte de ellas haciendo el esfuerzo para que sus singularidades fueran camufladas. Y segundo, porque la invisibilización de un espacio de la vida -en este caso a lo individual y privado- implicó costos no solo para las mujeres (aunque por cierto tuvo especificidades en sus casos) sino para una generación completa que vivió -o murió- su juventud sin permitirse las especificidades propias de la humanidad. La revolución fue un monstruo de la modernidad que, como tal, borró singularidades porque así se creía que se podía avanzar más pronto hacia el sueño insurreccional que borraría los malestares de esa misma humanidad que terminó obviando.

Con ello se produjo una paradoja: los malestares que se intentaron borrar mediante la revolución socialista de la modernidad, fueron combatidos a costa del nacimiento de malestares en quienes fueron engullidos por el ideal de la insurrección. Malestares propios de la imposibilidad final de olvidar sus singularidades que una y otra vez asomaron molestas, provocando tensiones, contradicciones y desacatos que hasta el presente no han sido resueltos. El trabajo realizado para terminar con los grandes malestares de la humanidad -siempre en abstracto, siempre en clave pública y colectiva-; implicó a quienes pertenecieron a esa vanguardia política cargar con nuevos malestares, esta vez concretos, individuales, privados.

Cuando estas mujeres militantes huyeron del cautiverio de las madresposas para asumir el rol de guerrillero -contradictorio con el lugar de la madresposa-; conocieron aspectos de sí mismas que de otra manera hubieran permanecido ocultos por las exigencias conyugales y maternas del sistema sexo género hegemónico. Sin duda, conocer nuevas capacidades en ellas implicó transformaciones en sí mismas, empoderamientos, autoestimas mejoradas ${ }^{97}$.

Y sin embargo no podríamos decir que accedieron a la emancipación total. Asumir el rol del combatiente, también implicó sus propios mandatos, rígidos, exigentes y coherentes con las exigencias de la moral revolucionaria militante guevarista, que enmarcó a las organizaciones de la Nueva Izquierda Revolucionaria de la época ${ }^{98}$. El lugar del combatiente implicó sus propias normas, expectativas y demandas. Las prófugas se liberaron y sin embargo no lograron la libertad total, sino cuotas de ella a cambio de nuevas restricciones.

En esta transgresión no encontraron un lugar propio, sino la posibilidad de sumarse a uno ya colonizado por la masculinidad hegemónica, el espacio de la militancia política y armada. Accedieron a ser guerrilleras en calidad de extranjeras, pero nunca pudieron cumplir con las exigencias como para ser -verdaderamente- un combatiente más. Para ello tendrían que haber nacido varones y haber sido criadas como tales.

A pesar de que la incorporación de estas mujeres fue a cambio de que estos espacios de lucha político militar -históricamente masculinos- permanecieran intocados, en la práctica estos se transformaron, no tanto por disposición de las organizaciones sino por la concretitud de temas surgidos por la convivencia entre mujeres y hombres en la militancia (relaciones amorosas, conflictos de poder, descendencia, problemas domésticos), como por la exigencia de las mujeres que -en algunos casos-

\footnotetext{
${ }_{96}$ Ciriza, Alejandra y Rodríguez, Eva, "Militancia política y subjetividad. La moral del PRT/ERP", Politicas de la memoria, 5 , Anuario de investigación del CeDInCI, Buenos Aires, 2004-2005, p. 7.

97 Vidaurrázaga, Tamara "De víctimas a protagonistas. Empoderamiento feminista en tres militantes del MIR", Género, 8(22). Universidad Federal Fluminense, Brasil, 2008.

98 Vidaurrázaga, 2015b, op. cit.; Vidaurrázaga, Tamara, 2012b, op. cit.; Ruíz, María Olga "Mandatos militantes, vida cotidiana y subjetividad revolucionaria en el Movimiento de Izquierda Revolucionaria de Chile (1965-1975)", Revista Austral de Ciencias Sociales, 28, pp. 163-182, 2015.
} 
reflexionaron colectivamente y demandaron ajustes de la organización a las necesidades que sus experiencias femeninas requerían aun siendo militantes.

Estas militantes fueron sujetas incómodas, pero que también incomodaron a la sociedad y a las propias orgánicas en las que se incluyeron como "uno más", con lo que transgredieron el binarismo propio del patriarcado y se instalaron en un No Lugar. Tal como señala la lingüista Deborah Cameron: "Los hombres sólo pueden ser hombres cuando las mujeres lo son sin un átomo de ambigüedad" 99 . Por tanto, cada vez que las militantes se salieron de su rol ejemplar, la pregunta que se abría era: ¿si estas mujeres no parecen tan mujeres, acaso los varones serán realmente varones? Ello podría explicar el malestar provocado en sus compañeros de militancia y, sobre todo, en la respuesta de los organismos represivos que las castigaron no solo por ser combatientes, sino también por ser mujeres salidas de sus lugares mandatados.

$\mathrm{Al}$ concluir la época de la revolución, y pasada la emergencia, las diferencias que pudieron ser obviadas para la orgánica y pospuestas por las mujeres durante la militancia, volvieron a evidenciarse, sobre todo al rehacer las vidas familiares relegadas a espacios en los que, la falta de estas mujeres, fue mucho más notoria que la de sus compañeros, y en las que debieron asumir los mayores costos de las opciones tomadas.

Aunque este no fue un desacato planificado y les produjo tensiones, al mismo tiempo las diferenció de sus congéneres y les abrió la posibilidad de conocer capacidades impensadas para quienes se mantuvieron en el cautiverio de la madresposa. Ello, porque -tal como señala Certau ${ }^{100}$ - el viaje hacia lo incierto posibilita la conformación de un sujeto, por más que este no encuentre un lugar propio y solo acceda al No Lugar en este tránsito inacabado. Podríamos señalar, en palabras de Gloria Anzaldúa, que estas mujeres adquirieron una conciencia mestiza con capacidad para estar en dos orillas al mismo tiempo ${ }^{101}$, moviéndose en las fronteras sin encontrar lugar propio pero -también- con la libertad de movimiento propio de viajeras en tránsito y que caracterizaría al No Lugar sexo genérico.

Militaron, así, en calidad de extranjeras, siempre ajenas al espacio político y constantemente cuestionadas, intentando alcanzar un ideal de combatiente que era masculino y, por tanto, inalcanzable. Y, sin embargo, es evidente que el solo habitar ese espacio negado implicó desestabilizarlo y provocar cambios o al menos dudas, tanto en ellas como en la organización y sus compañeros. Surge entonces la pregunta ¿es posible la mujer militante normalizada, sin actuaciones de por medio, si esa militancia excluye las necesidades de las condiciones y deseos de las mujeres que participan en ella, exigiéndoles un disfraz masculino de guerrillero para ser aceptadas como tales? La interrogante es más pertinente aún si esa militancia excluye las necesidades de lo privado e individual -propias del cuerpo del deseo y de la humanidad completa- y niega este espacio como lugar en que también existen relaciones de poder necesarias de revisar y transformar si, lo que se busca, es revolucionar la sociedad a construir.

Bibliografía

\section{Fuentes impresas:}

Anzaldúa, Gloria, Borderlands/La Frontera: The New Mestiza, San Francisco, Aunt Lute, 1987.

Beltrán, Elena, "Público y privado (Sobre feministas y liberales: argumentos en un debate acerca de los límites de lo político)", Debate Feminista, año 9, volumen XVIII, México, 1998.

Cameron, Deborah, Feminism and Linguistic Theory, Londres, Macmillan, 1985.

Castillo, Carmen y Echeverría, Mónica, Santiago-París. El vuelo de la memoria, Santiago, LOM, 2002.

Castillo, Carmen, Un día de octubre, Santiago, LOM, 2013.

${ }_{99}$ Cameron, Deborah, Feminism and Linguistic Theory, Londres, Macmillan, 1985, p. 156

100 Certau, op. cit.

101 Anzaldúa, Gloria, Borderlands/La Frontera: The New Mestiza, San Francisco, Aunt Lute, 1987. 
Casullo, Nicolás, Las Cuestiones, Buenos Aires, Fondo de Cultura Económica, 2007.

Certeau, Michel, La invención de lo cotidiano, México, D.F, Universidad Iberoamericana, A.C., pp. 229, 1996.

Ciriza, Alejandra y Rodríguez, Eva, "Militancia política y subjetividad. La moral del PRT/ERP”, Políticas de la memoria, 5, Anuario de investigación del CeDInCI, Buenos Aires, 2004-2005.

De Beauvoir, Simone, El segundo sexo, México, Debolsillo, 2013.

El Rebelde, No 18, febrero, 1972.

El Rebelde, “Liberación de la mujer", Nº 28, mayo, 1972.

Naranjo, P., Ahumada, M., Garcés, M. y Pinto, J. Miguel Enríquez, el proyecto revolucionario en Chile. Santiago, LOM, 2004.

Fraisse, Geneviève, Los dos gobiernos: la familia y la ciudad, Madrid, Cátedra, 2003.

Gaviola, Edda, Largo, Eliana y Palestro, Sandra, Una historia necesaria: mujeres en Chile 1973-1990, Santiago, LOM, 2007.

Goicovic, Igor, Movimiento de Izquierda Revolucionaria, Santiago, Escaparate, 2012.

Lagarde, Marcela, Los cautiverios de las mijeres: madresposas, monjas, putas, presas y locas, Madrid, HORAS y horas, 2011.

Longoni, Ana, "El mandato sacrificial", Revista Ciencias Sociales, 67, julio, 2007.

López, Beatriz, ;Pueblo, conciencia, fusil, MIR, MIR! Representaciones y construcciones de masculinidad/es como eje de identidad. Movimiento de Izquierda Revolucionaria, MIR:1967-1974. Tesis para optar al grado de Licenciada en Historia. Universidad Diego Portales, Santiago, 2010.

Löwy, Michael, El Pensamiento Del Che Guevara, Buenos Aires, Siglo XXI, 1985.

McDowell, Linda, Género, identidad y lugar: un estudio de las geografías feministas, Madrid, Cátedra, 2000.

Molina, Cristina, "Dialéctica feminista de la Ilustración", Barcelona, Antrophos, Madrid, Comunidad de la mujer, 1994.

Palominos, Eva, Vuelo de Mariposa, una Historia de amor en el MIR, Santiago, Escaparate, 2007.

Pateman, Carole, El contrato sexual, Barcelona, Anthmpos, México, Universidad Autónoma Metropolitana - Iztapalapa, 1995.

Pinto, Julio y Leiva, Sebastián "Punto de quiebre. El MIR en los ochenta”, Verónica Valdivia, Rolando Álvarez, Julio Pinto, Karen Donoso, Sebastián Leiva (eds.), Su revolución contra nuestra revolución, Volumen II, La pugna marxista-gremialista en los ochenta, Santiago, LOM, 2008.

Rabotnikof, Nora, "Privado-público", Debate Feminista, año 9, volumen XVIII, México, 1998.

Ruíz, María Olga "Mandatos militantes, vida cotidiana y subjetividad revolucionaria en el Movimiento de Izquierda Revolucionaria de Chile (1965-1975)", Revista Austral de Ciencias Sociales, 28, pp. 163-182, 2015 .

S/A, “Entrevista a Miguel”, en Punto Final, julio, 1969

Salazar, Gabriel y Pinto, Julio, (Con la colaboración de Muñoz, V. y Toro, M. S.),. Historia contemporanea de chile. Tomo V. Niñez y juventud, Santiago, LOM, 2002.

Sandoval, Carlos, Movimiento de Irquierda Revolucionario 1965-1970. Coyunturas, documentos y vivencias, Tomo I, Santiago, Quimantú, 2014.

Vidaurrázaga, Tamara, Mijeres en Rojo y Negro. Reconstrucción de memoria de tres mujeres miristas, Santiago, Escaparate, 2006.

"La escisión entre lo individual y lo colectivo en la moral revolucionaria militante de la Nueva Izquierda", Sujeto, Subjetividad y Cultura, 4, Escuela de Psicología, Universidad Arcis, 2012b. "Subjetividades sexo genéricas en mujeres militantes de organizaciones políticomilitares de izquierda en el Cono Sur", La Ventana, 41, enero-junio, Guadalajara, 2015a.

"El pecado pequeño burgués en las organizaciones de la nueva izquierda revolucionaria latinoamericana. MIR chileno y MLN-T uruguayo", Estudios, 34, Julio-Diciembre, 2015b. 
Vidaurrázaga, Tamara. "Pequeños compañeritos: Los hijos del MIR y Montoneros en los hogares colectivos de Cuba" en Exilios del cono sur: género, generación y clases, Jimena Alonso, María Eugenia Horvitz y Carla Peñaloza, Santiago, Cuarto Propio, 2018, en prensa.

\section{Fuentes electrónicas o digitalizadas:}

Aguiló, Macarena, El edificio de los chilenos, 2010

Amorós, Celia, "Espacio público, espacio privado y definiciones ideológicas de 'lo masculino' y 'lo femenino"', Feminismo, igualdad y diferencia, México, UNAM, 1994. Disponible en http://www.laneta.apc.org/cidhal/lectura/identidad/texto6.htm

Ghio, Bettina y Di Piero, Norma, "Dar al término 'mujer comprometida' toda su amplitud poética", entrevista a Carmen Castillo, 2013. Disponible en http://mujeresporlademocracia.blogspot.cl/2013/03/entrevista-con-la-realizadora-carmen.html Hartmann, Heidi, "Un matrimonio mal avenido: hacia una unión más progresiva entre marxismo y feminismo", Zona Abierta, $\mathrm{n}^{\circ}$ 24, $1980 . \quad$ Disponible en http://www.fcampalans.cat/archivos/papers/88.pdf.

Schmucler, Héctor, "Testimonio de los sobrevivientes". Controversia, 9-10, 1980. Disponible en http://americalee.cedinci.org/wp-content/uploads/2016/08/CONTROVERSIA-9-10.pdf

Smithson, Robert, A provisional theory of Non-sites, 1968. Disponible en:

http://www.robertsmithson.com/essays/provisional.htm. Acceso el: 30/06/2014.N

\section{Entrevistas:}

Alejandra, 13 de diciembre de 2013, comunicación personal.

Álvarez, Ángeles, 2 de julio de 2014, comunicación personal.

Aránguiz, Soledad, 26 de octubre de 2002, comunicación personal.

Becker, Nubia, 13 de diciembre de 2013, comunicación personal.

Chacaltana, Cristina, 22 de febrero de 2003, comunicación personal.

Díaz, Gladys, 15 de enero de 2014, comunicación personal.

Matamala, María Isabel, 20 de noviembre de 2013, comunicación personal.

Marta, 21 de julio de 2014, comunicación personal.

Ortega, Myriam, 6 de febrero de 2014, comunicación personal.

Ojeda, Arinda, 16 de noviembre de 2002, comunicación personal.

Sepúlveda, Lucía, 11 de diciembre de 2013, comunicación personal.

Zalaquett, Patricia, 17 de enero de 2014, comunicación personal. 